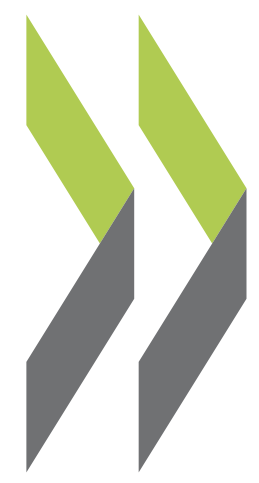

OECD Social, Employment and Migration Working Papers No. 220

\title{
Tackling child poverty in Canada
}

\section{Olivier Thévenon}


30 October 2018

DIRECTORATE FOR EMPLOYMENT, LABOUR AND SOCIAL AFFAIRS EMPLOYMENT, LABOUR AND SOCIAL AFFAIRS COMMITTEE

Tackling child poverty in Canada

OECD SOCIAL, EMPLOYMENT AND MIGRATION WORKING PAPERS No. 220

JEL Classification: J13; I32; I38

For Further Information contact:

Olivier Thévenon (Olivier.THEVENON@,oecd.org),+33 (1) 85556004

All Social, Employment and Migration Working Papers are now available through the OECD website at www.oecd.org/els/workingpapers.

JT03438493 


\title{
OECD Social, Employment and Migration Working Papers
}

\author{
www.oecd.org/els/workingpapers
}

OECD Working Papers should not be reported as representing the official views of the OECD or of its member countries. The opinions expressed and arguments employed are those of the author(s).

Working Papers describe preliminary results or research in progress by the author(s) and are published to stimulate discussion on a broad range of issues on which the OECD works. Comments on Working Papers are welcomed, and may be sent to els.contact@oecd.org.

This document and any map included herein are without prejudice to the status of or sovereignty over any territory, to the delimitation of international frontiers and boundaries and to the name of any territory, city or area.

\section{Note on Israeli Statistical data}

The statistical data for Israel are supplied by and under the responsibility of the relevant Israeli authorities. The use of such data by the OECD is without prejudice to the status of the Golan Heights, East Jerusalem and Israeli settlements in the West Bank under the terms of international law.

(C) OECD 2018

You can copy, download or print OECD content for your own use, and you can include excerpts from OECD publications, databases and multimedia products in your own documents, presentations, blogs, websites and teaching materials, provided that suitable acknowledgment of OECD as source and copyright owner is given. All requests for commercial use and translation rights should be submitted to rights@,oecd.org. 


\section{Acknowledgements}

The report was prepared under the overall supervision of the OECD Secretary-General, Angel Gurría, and the Special Counsellor to the Secretary-General, Gabriela Ramos.

The OECD Directorate for Employment, Labour, and Social Affairs (ELS) prepared this report under the senior leadership of Stefano Scarpetta (Director of ELS), Mark Pearson (Deputy Director of ELS) and Monika Queisser (Senior Counsellor, Head of the OECD Social Policy Division).

The report was written by Olivier Thévenon under supervision of Willem Adema, and received contributions from Chris Clarke, Thomas Manfredi, and Sarah Strapps (OECD Social Policy Division). Employment and Social Development Canada provided the data from the Survey of labour and Income Dynamics, the Canadian Income Survey and the Canadian Survey of Economic Well-Being 2013. Patrick Bussière, Maxime Fougère, BenoîtPaul Hébert and Sid Ali Amedah (Employment and Social Development Canada) contributed to the report and commented on earlier drafts. Andrew Barker from the OECD Canadian desk is also deeply thanked for his valuable comments.

The financial support provided by Employment and Social Development Canada for this report is gratefully acknowledged. 


\section{Abstract}

This paper compares the situation of children in Canada relative to other OECD countries in terms of child poverty and well-being. First, trends in child poverty and living standards since 2007, i.e. one year before the onset of the Great Recession, are described. An overview of children's material deprivation and of key indicators of child well-being is also provided. The paper discusses the observed poverty trends in relation to policies implemented to combat it by federal authorities. Some priorities for action to make the alleviation of child poverty more effective are discussed. 


\section{Résumé}

Ce document compare la situation des enfants au Canada par rapport aux autres pays de l'OCDE en matière de pauvreté des enfants et de bien-être. Sont d'abord décrites les tendances de la pauvreté et de niveau de vie des enfants depuis 2007, année antérieure à la Grande récession. Un panorama des privations matérielles subies par les enfants et des principaux indicateurs de bien-être des enfants disponible au niveau international est aussi proposé. Le document discute les évolutions constatées de la pauvreté au regard des politiques mises en œuvre pour la combattre au niveau du gouvernement fédéral. Certaines priorités d'action pour rendre la lutte contre la pauvreté des enfants plus effective sont discutées. 


\section{Table of contents}

OECD Social, Employment and Migration Working Papers..................................................................... 2

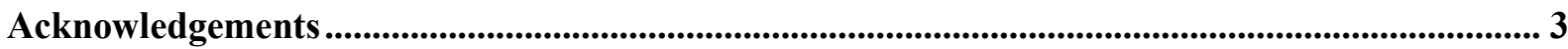

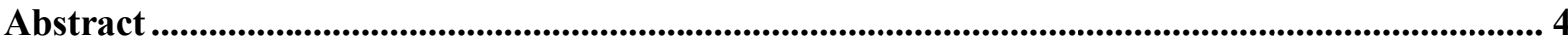

Résumé .................................................................................................................................................. 5

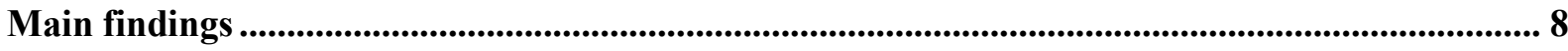

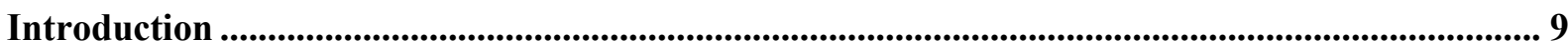

1. Child poverty in Canada........................................................................................................................... 10

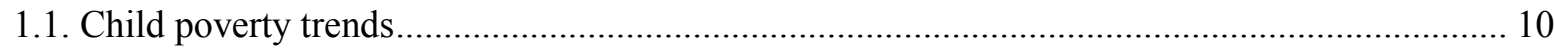

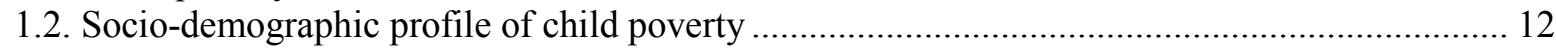

2. Changes in children's living standards between 2007 and 2014 .............................................. 16

3. Patterns of children's material deprivation ........................................................................................... 19

4. Child Well-Being: How does Canada compare to other OECD countries? ................................... 24

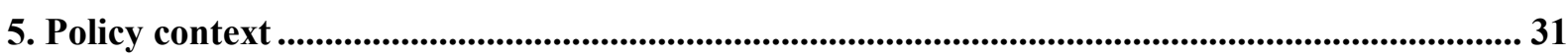

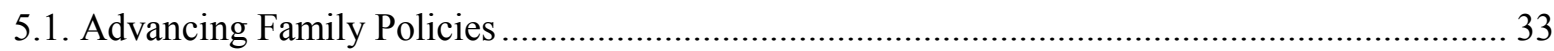

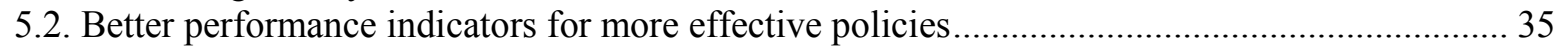

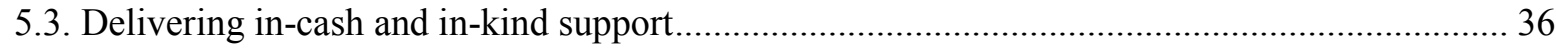

Annex A. Background information on the policy context in Canada.................................................. 40

Annex B. Changes in children's living standards between 2007 and 2014..................................... 54

Methodology for the decomposition analysis of changes in children's income ................................... 60

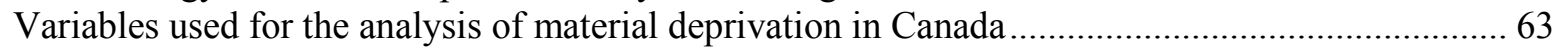

\section{Tables}

Table 1. Percentage of children in low-income by level of education of parents, 2014 ....................... 13

Table 2. Material deprivation rates according to the diverse dimensions Canada 2013 ...................... 20

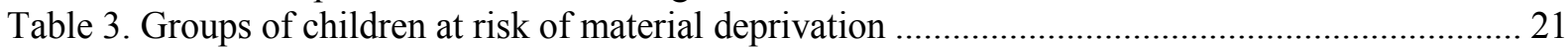

Table 4. Characteristics of the groups of materially deprived children in Canada................................ 22

\section{Figures}

Figure 1. In Canada, around 1 in 6 children are income poor in relative terms .................................. 10

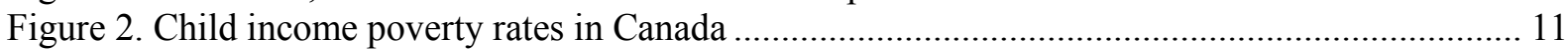

Figure 3. Changes in living standard of children - Canada (2007-2014) ................................................ 17

Figure 4. How Canada compares to other OECD countries on 19 key measures .................................. 25

Figure 5. Mathematics performance at age 15 (PISA), by migrant status ........................................... 26

Figure 6. Adolescents who expect to complete a university degree, by migrant status ........................ 26 
Figure 7. Adolescents with books for school work at home, by ESCS quartile .................................. 27

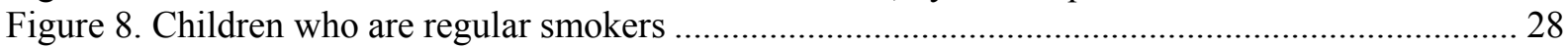

Figure 9. Adolescents who report being the victims of bullying, by education of parents ................... 29

Figure 10. Adolescents regularly engaging in vigorous exercise, by gender ..................................... 30

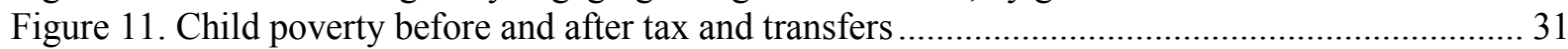

Figure 12. Out of pocket costs of childcare for low earner families ................................................. 34

Figure A 1. Average Effective Tax Rates for a transition into full-time work, 2015 .......................... 43

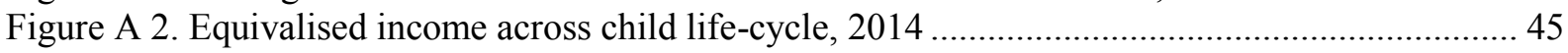

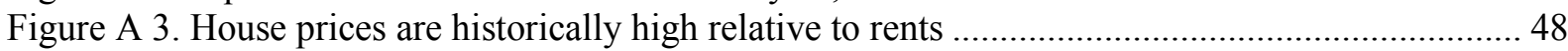

Figure A 4. Housing cost burden is considerably higher for the poorest households, $2011 \ldots \ldots \ldots \ldots \ldots . . .50$

Figure B.1. Changes in living standard of children in two parent families - Canada (2007-2014) ...... 57

Figure B.2. Changes in living standard of children in single parent families - Canada (2007-2014) ... 59

\section{Boxes}

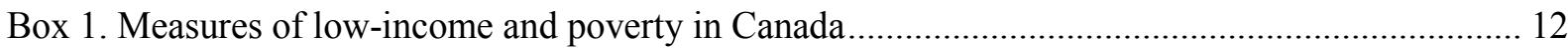

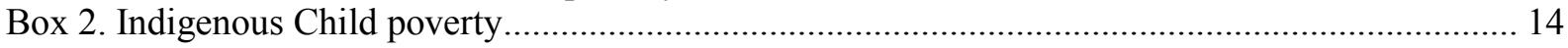

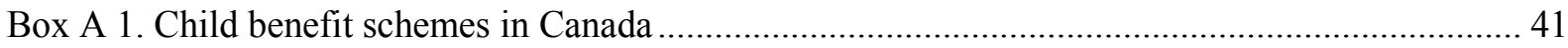

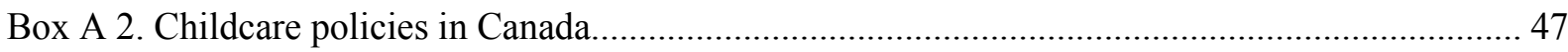

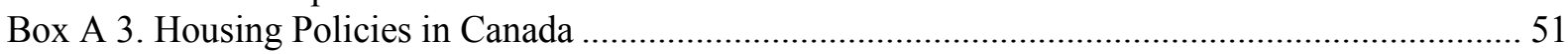




\section{Main findlings}

- Child poverty in Canada is close to the OECD average: around 1 in 7 children are income-poor, on average, across the country.

- Joblessness is strongly associated with child poverty: 9 out of 10 children in households where no parent has a job are income-poor. Policies aimed at supporting parents' labour market attachment could help support some income poor families improve their standard of living.

- Poverty in Canada is more prevalent among certain groups than others - children of single parents, indigenous children, and children with an immigrant background are more likely to be living in income poverty. Poverty reduction policies should focus on interventions that would support better outcomes for these groups.

- In Canada, as elsewhere, more income poor children live in rental accommodation, as opposed to homes that are owned by their parents. As home ownership becomes more inaccessible for families at the lower-end of the socio-economic distribution, housing policy interventions should focus on outcomes that protect low-income tenants from rent increases. Targeting housing benefits towards low-income families, increasing social housing stock and prioritising placement of families with the greatest needs are options that can better help meet the housing needs of poor families.

- In August 2018, Government of Canada launched first Poverty Reduction Strategy. The reduction of child poverty could be identified as a specific objective of the recently launched poverty reduction strategy. The development of measures of children's exposure to income poverty and of unmet needs in terms of food, health, education and housing would make it possible to set targets for children and monitor progress for this particular population group.

- Assessing the impact of investments in early learning and childcare should be included as part of the Poverty Reduction Strategy announced in August 2018. The number of childcare places created, access for low-income children, and the quality of services provided will be important metrics to monitor in order to measure the results of public spending on poverty reduction.

- Families with very low-incomes and jobless parents, in particular, are at greater risk of living in low-quality housing and experiencing deprivation in terms of food and/or dental care. In this case, getting out of poverty and its consequences presupposes that barriers to employment are addressed, and that obstacles that limit access to care, quality housing can be eliminated, and that financial aid can be granted. For this, coordination between employment, health, housing or social services is necessary, which can be ensured, for example, by a management on a case-bycase basis and the implementation of community-based single-entry points of service. 


\section{Introduction}

1. Childhood is a critical period for the development of human and social capital of individuals. Unfortunately, however, far too many children do not get the best possible start in life, as they experience poverty in the early years of life. Poverty has a big impact on children in different ways: it affects their material living conditions, the quality of the relationships with their parents, their health and educational outcomes as children and, later in life, their integration into the labour market and career prospects. Effectively combating child poverty improves family and child well-being, and can form a basis for sustainable inclusive growth in future.

2. For many countries, child poverty is not a new policy issue, and it has received renewed attention at the international level with the 2015 UN Sustainable Development Goals target to halve child poverty by national definitions by 2030 . Moreover, children often show a risk of poverty that is higher than for other population groups and many low-income families have experienced a decline of living standards, which calls for strengthening efforts made to alleviate child poverty.

3. Different demographic, economic and institutional factors help explain the different trends in child poverty in OECD countries (Thévenon et al., 2018). Nevertheless, each country has its own history and institutions to understand and identify policy levers that can reduce child poverty and/or limit its impact on children's well-being.

4. This report examines the situation in Canada with respect to child poverty, material deprivation affecting families, and the well-being of children and adolescents based on indicators available for comparative analysis. It also reports on policy developments to understand child poverty trends and identify some policy directions that can help reduce child poverty in the future.

5. The report is organised as follows. The first section reviews the main trends regarding child income poverty, and it also it reports on changes in the standard of living of children from low-income families from the pre-crisis period in 2007 to 2014 (section 2). The third section describes the material deprivations of the families where children live, whether or not they are income poor. Several groups of children are identified according to whether or not they are deprived in one or several dimensions. The analysis of material deprivation profiles of children enables identifying what policies are needed to complement financial assistance, such as improving access to basic resources for nutrition, clothing, education, housing and promoting access to leisure activities for all children. The fourth section examines the situation in Canada relative to other OECD countries with respect to indicators reflecting different dimensions of child well-being. Finally, the last section describes the context of family support and suggests policy directions that can contribute to a national strategy to combat child poverty. More detailed information on the policy context and trends children's living standards is provided in Annexes A and B of this document. 


\section{Child poverty in Canada}

\subsection{Child poverty trends}

6. Measuring and comparing child poverty (or any other population group) requires arbitrarily defining an income threshold below which all members of a household will be considered poor. This level of income is meant to synthesize differences in purchasing power and standard of living between households and for this reason is used as a proxy to categorize household members as poor or not. This aggregation within a single income indicator is difficult to achieve, especially in a country like Canada with a particularly large geographical area and regions with very different living conditions and costs. For this reason, it is useful to consider additional criteria to identify poor households, and take into account needs that may vary according to family types and regions (Box 1).

7. The relative poverty indicator measures the proportion of people living below a fixed poverty line relative to the income distribution in each country - here the line is set at $50 \%$ of median income. This measure is particularly useful for international comparisons as it allows for national specificities in the distribution of income to be taken into account while providing an identical point of comparison.

Figure 1. In Canada, around 1 in 6 children are income poor in relative terms

Share (\%) of children (0-17) with an equivalised post-tax-and-transfer income of less than $50 \%$ of the national annual median equivalised post-tax-and-transfer income, $2007 \mathrm{a}, 2015-16^{\mathrm{b}}$ or nearest available year

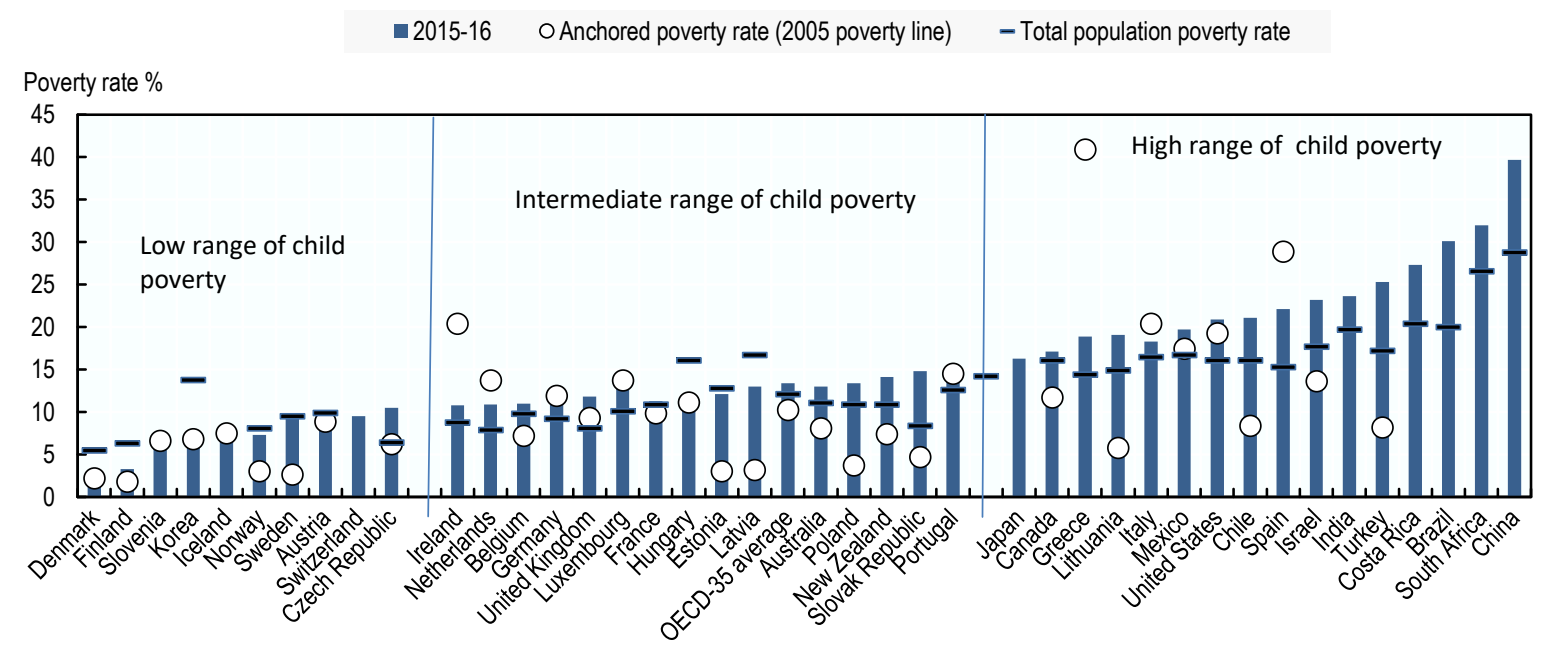

Notes: a) 2008 for Australia, France, Israel, New Zealand, Norway, Sweden and the United States; 2009 for Chile; 2010 for the Netherlands; b) ; b) 2012 for Japan; 2013 for Brazil, China;2014 for Australia, Iceland, New Zealand and Mexico; 2017 for Costa Rica. Countries are categorised in low and high if they are half a standard deviation below or above the OECD average.

Source: OECD Income Distribution Database.

8. According to relative poverty measures, nearly 1 in 7 children is income-poor on average in the OECD, though with large disparities across countries (Figure 1). For example, more than one in five children are income-poor in Chile, Israel, Spain, Turkey and the United States, which is almost ten times higher than the child poverty rate in Denmark. Within this 
spectrum, child poverty in Canada is higher than the OECD average: a bit more than 1 in 6 children are income-poor, on average, across the country, children being as affected by poverty as the average of the total population. The child poverty rate, moreover, has remained fairly stable since the beginning of the crisis, rising by only 0.3 percentage points since 2007 .

9. By "anchoring" the poverty line at a fixed level, it is possible to estimate the proportion of children who have a "standard of living" lower than or equal to the poverty line that prevailed a few years or decades earlier. Figure 2 shows the poverty rate based on a poverty line anchored in its 2005 value (this reference is re-evaluated each year to take price inflation into account). The poverty rate obtained with the 2005 poverty line is much lower than the relative poverty rate obtained with a 'floating' poverty line in Figure 1, due to the marked rise in median income showing that the standard of living of poor children has improved over time since 2005.

Figure 2. Child income poverty rates in Canada

Share (\%) of children (0-17) and of the total population with an equivalised post-tax-and-transfer income of less than $50 \%$ of the national annual median, 2015

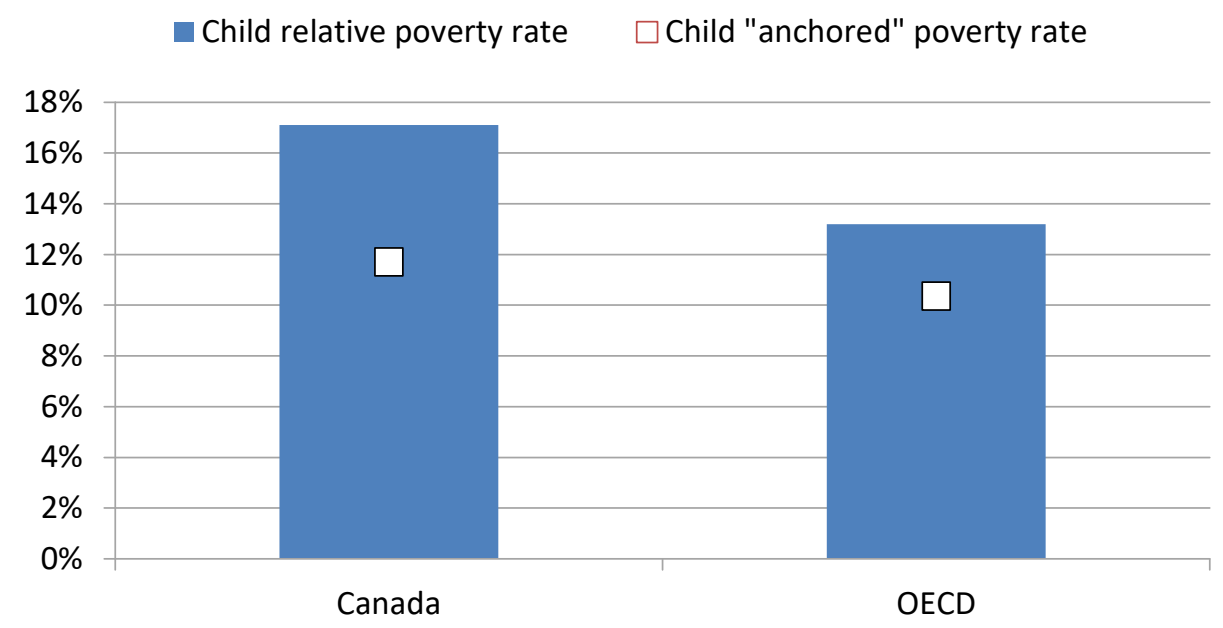

Note: The 'anchored' poverty rate sets the poverty line at its 2005 level with yearly adjustments for price inflation. Source: OECD Income Distribution Database.

10. Poverty is often a transitory situation in Canada. For example, over the period 20052010 , the proportion of low-income Canadians is halved after one year, and only $1.5 \%$ of them lived in low-income for up to 6 years based on the Low-income Cut-Offs (LICO) after tax (Government of Canada, 2016 $[1]$ ). 


\section{Box 1. Measures of low-income and poverty in Canada}

The Government of Canada does not have an official definition of poverty. However, poverty is often assessed by measuring the number of Canadians with low-incomes. There are several indicators used to measure low-income:

\section{Low-income cut-offs}

The Low-income Cut-offs are income thresholds below which a family will devote a larger share of its income on the necessities of food, shelter and clothing than the average family. It is a relative measure of low-income; as a family is considered low-income if it spends 20 percentage points more on these necessities than the average family. The Low-income Cut-offs are adjusted for seven family sizes and five different community sizes to capture differences in the cost of living.

Since data is available as far back as 1976, it is frequently used to examine lowincome trends over several years.

\section{Low-income measure - relative poverty rate}

The Low-income Measure defines low-income as being below a fixed percentage of income. A household is considered low-income if its income is below $50 \%$ of median household incomes. It is, therefore, the relative measure of poverty that is conventionally used for OECD comparisons.

\section{Market basket measure}

There are sizeable variations in the costs of living and socio-economic circumstances across Canada. Such concern is addressed by the use of the Market Basket Measure (MBM), which sets many low-income thresholds reflecting the estimated cost of a specific set of goods and services that represent a basic standard of living in a specific area.

A family is considered low-income if it does not have enough money to buy these specific goods and services in its community. This indicator is available for 49 different communities across Canada and is more sensitive to differences in the cost of living. Moreover, when MBM thresholds are applied to infer national low-income rates, these are lower that the estimates obtained from applying a "floating" relative income approach. In 2015, 12.2\% (4.2 millions) of people were categorised in low-income when the MBM is applied, against $14.2 \%$ (4.6 millions) with the conventional relative poverty measure.

For the first time in August 2018, the government of Canada decided to set an official poverty measure which will be calculated using the market Based Measure (Employment and Social Development Canada, 2018 [2]

\subsection{Socio-demographic profile of child poverty}

11. Families in Canada are diverse in their composition and vary across the provinces and territories. In 2016, slightly less than $20 \%$ of children lived in single parent families (more than two-thirds of which are female led households) (Statistics Canada, 2017 [3]), and close to $40 \%$ of income poor children lived in single parent families. Though relatively stable 
over time, the proportion of children living in single parent families in Canada is highest in the Atlantic Provinces where median incomes are lowest (Statistics Canada, 2016) and in northern Canada.

12. The risk of poverty is higher overall for single-parent families than for two-parent families, but it is highly dependent on the parent's employment status: in 2015 , while $92 \%$ of single-parent families are poor when the parent is not working, only one-third of single-parent families are income poor when the parent works (OECD Income distribution Database). Taking a longer-term perspective, the proportion of children in single-parent families living in low-income households has halved since the mid-1990s (Government of Canada, 2016 $6_{[1]}$ ). In addition, the increase in the Canada Child Benefit payment adopted in 2016 may have helped reduce the poverty rate from its 2015 level.

13. Parental joblessness is an important determinant of the risk of poverty. In Canada, $75.6 \%$ of two-parent jobless households and $92.5 \%$ of single-parent jobless households are income-poor which is far above the OECD averages of $60 \%$ and $64 \%$ respectively.

14. More than two-thirds of poor children live with a parent with some tertiary education. Nevertheless, the risk of poverty is much lower when the father or mother has tertiary education. For example, about $8 \%$ of children are poor when the father has a higher education level, while more than $20 \%$ of children whose father has a lower secondary school diploma are poor (Table 1).

Table 1. Percentage of children in low-income by level of education of parents, 2014

\begin{tabular}{|c|c|c|c|c|c|}
\hline & & \multicolumn{4}{|c|}{ Highest level of education of mother } \\
\hline & & Less than upper secondary & Upper secondary & Tertirary & Total \\
\hline \multirow{4}{*}{$\begin{array}{c}\text { Low-income } \\
\text { status }\end{array}$} & No & 68,7 & 80,9 & 90,6 & 87,2 \\
\hline & Yes & 31,3 & 19,1 & 9,4 & 12,8 \\
\hline & & \multicolumn{4}{|c|}{ Highest level of education of father } \\
\hline & & Less than upper secondary & Upper secondary & Tertirary & Total \\
\hline \multirow[t]{2}{*}{$\begin{array}{c}\text { Low-income } \\
\text { status }\end{array}$} & No & 79,1 & 86,9 & 92,1 & 90,1 \\
\hline & Yes & 20,9 & 13,1 & 7,9 & 9,9 \\
\hline
\end{tabular}

Note: Data from Statistics Canada on tertiary education do not distinguish between some adult education and occupational preparation programmes, so international comparisons of tertiary education systems should be handled with some caution.

Source: 2014 Canadian Income Survey.

15. According to the 2016 Census, 2.2 million children in Canada (37.5\% of all children) under the age of 15 were foreign born or had at least one foreign born parent (Statistics Canada, 2017 $[4]$. The proportion of children with an immigrant background is on an upward trajectory and is expected to increase to between $39.3 \%$ and $49.1 \%$ by 2036 (Statistics Canada, $\left.2017_{[5]}\right)$. While poverty rates have been declining in Canada, immigrants face higher rates of poverty than their Canadian-born counterparts, and low income rates among recent immigrants in 2010 was 2.6 times higher than the Canadian-born population (Picot and Hou, $\left.2014_{[6]}\right)$.

16. Furthermore, Indigenous children in Canada face a relatively high risk of living in low income and poverty (Box 2). Addressing Indigenous child poverty is done through programmes delivered nationally and at the provincial level, as well as through targeted initiatives that include childcare programs, labour force development programs, and social transfers to indigenous communities. 


\section{Box 2. Indigenous Child poverty}

1.7 million people in Canada report having an Indigenous identity, accounting for $4.9 \%$ of the population (Statistics Canada, 2017 $7_{[4]}$ ). The Government of Canada does not conduct any comprehensive survey that captures poverty data among all Indigenous communities.

The 2016 Census indicates that $30 \%$ of Aboriginal children live in a low-income household, with important variations across communities and regions (Statistics Canada, $\left.2017_{[7]}\right)$. Statistics Canada notifies that these estimates are affected by the incomplete enumeration of certain Indian reserves and Indian settlements in the Census of Population. Furthermore, the low-income concepts are not applied in the territories and in certain areas, as the existence of substantial in-kind transfers and sizeable barter economies as well as consumption from own production make the interpretation of low-income statistics more intricate.

The Canadian Human Rights Tribunal, (2017) found that First Nations children and families are denied equal child and family services, and that policy design and funding formulas in place result in denials of services that are based on race or ethnic origin. The ruling goes on to state that "these adverse impacts perpetuate the historical disadvantage and trauma suffered by Indigenous peoples, in particular as a result of the Residential Schools system". The residential schools system was part of a century's long policy of assimilation of Indigenous peoples that entailed the removal of children from their families for the purpose of education. Conditions in schools inflicted trauma on many Indigenous children through harsh discipline, the abnegation of culture and identity, and pervasive physical and sexual abuse. Survivors of the residential schools system initiated the largest class-action settlement in Canadian history whereby a multi-billion dollar fund was established to help former students in their recovery and led to the creation of the Truth and Reconciliation Commission of Canada in 2008.

The Truth and Reconciliation Commission of Canada, (2015) identifies 94 calls to action to redress the legacy of Residential Schools and advance the process of Canadian reconciliation. Improving child welfare is the top priority, and the calls to action provide a comprehensive roadmap that aims to eliminate the gaps in outcomes between Indigenous and non-Indigenous Canadians.

A report commissioned by the Premiers of all the Canadian provinces and territories by a coalition of Indigenous advocacy groups (Aboriginal Children in Care Working Group, 2015), shows that Indigenous children are greatly overrepresented among children in Canada's child welfare systems. There is variation across provinces and territories but in Alberta for example, $9 \%$ of children are Indigenous; while $69 \%$ of children in care are Indigenous.

Addressing poverty among indigenous children requires a holistic approach that includes community level and family level interventions through cash and in-kind supports. Improving housing, closing gaps in education quality and increasing completion rates, as well as addressing health and social service provisions needs of indigenous people is essential to addressing some of the material deprivation issues of indigenous children and communities.

Through investments made in Budget 2017 and Budget 2018, the Government announced dedicated funding of over $\$ 1.7$ billion for Indigenous housing. Budget 2018 also introduced the new Indigenous Skills and Employment training Program to replace the Aboriginal Skills and Employment Training Strategy with an incremental investment of almost $\$ 450$ million over five years and nearly $\$ 100$ million per year ongoing. 
17. In Canada, the proportion of children in poor homeowner families declined between 2007 and 2014 by 7 percentage points from $52.6 \%$ to $45.5 \%$. The year over year increases in home prices in most parts of the country may be crowding out lower-income families from the housing market even in a low mortgage-rate environment. Nevertheless, rents have continued to grow in real terms even in recent years, and although this growth is less strong than that of house prices, the drop in the rental vacancy rate to $2.9 \%$ indicates that demand is outpacing growth in supply which could, in turn lead to upward pressure on rents (Canada Mortgage and Housing Corporation, 2017) (OECD, 2018[8]). 


\section{Changes in children's living standards between 2007 and 2014}

18. Child poverty trends have been stable since the early 2000s. However, families were unevenly affected by the Great Recession, as shown by the analysis of trends in family income, family composition, parental labour market attachment, parental education and home ownership. The evolutions described here stop at 2014-15 and therefore do not reflect the effect of the measures adopted since 2016, including the Canada Child Benefit in 2016, which was expected to lift 300,000 children out of poverty (Box A.1).

19. Unlike in other countries, the standard of living of children in poor two-parent families in Canada improved between 2007 and 2014, while it declined for children in singleparent families (Figure 3, and Annex B provides detailed analysis of changes in children's living standard along the income distribution).

20. For children in two-parent families, both market and disposable income increased over this period at all levels of the income distribution. For instance, the maximum income of families with the poorest $25 \%$ of children (i. e. the 25 th percentile) increased by almost $6.5 \%$, while market incomes increased by $3.5 \%$ (Figure 3, Panel A) - the increase in disposable income being of comparable magnitude throughout the income distribution (see Annex B).

21. The rise in the standard of living for poor children in two-parent families is partly explained by a positive change in the characteristics of households where poor children live (Figure 3, Panel A). In particular, the proportion of these poor children with a father and/or mother with higher education has increased from 47 to $60 \%$ between 2007 and 2014, and these parents are relatively better off among low-income families.

22. An even larger part of the gain in standard of living is explained by a change in the effect of household characteristics on the position of children in the distribution of income (shown in Figure B.1. Changes in living standard of children in two parent families - Canada (2007-2014)

23. and Figure B.2. Changes in living standard of children in single parent families Canada (2007-2014)

24. in Annex B). One trend dominates in particular: the relative gain in income $(+13 \%)$ for children whose parents own the home compared to poor families who rent their homes but who otherwise share the same characteristics (Annex B). Declines in home ownership tend to push the standard of living down. The proportion of poor children in a two-parent family renting a dwelling increased sharply, from $36 \%$ in 2007 to $50 \%$ in 2014 . The sharp rise in house prices contributes to the increasing exclusion of poor families from home ownership.

25. Changes in parental employment (such as job loss or reduced earnings) in poor twoparent families tend to push the standard of living down. First, the drop in the number of poor children with a working father: $26 \%$ of children in the first quartile of families with two parents had a father out of employment in 2014, compared to $18 \%$ in 2007 . In addition, $53 \%$ of poor children have a father employed full time full year in 2014, compared to $66 \%$ in 2007. 


\section{Figure 3. Changes in living standard of children - Canada (2007-2014)}

Panel A: Contribution of changes in family and work characteristics to changes in living standard of poor children in two-parent families

Market income

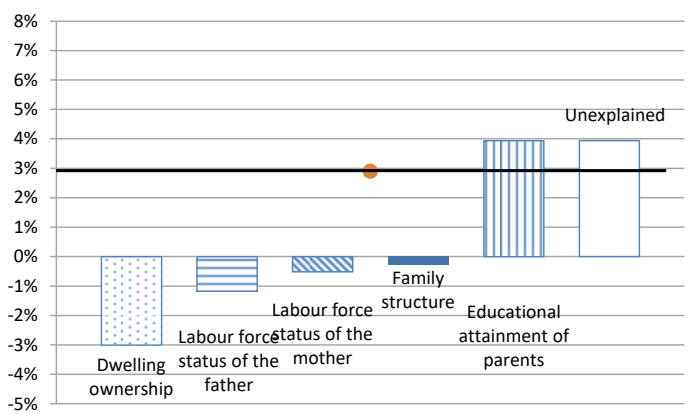

Disposable income

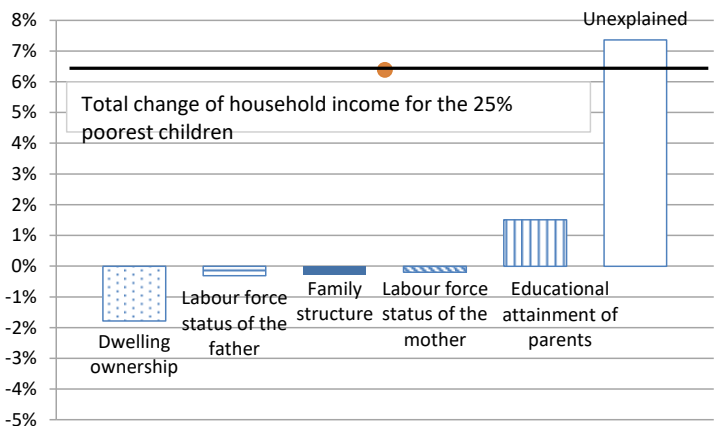

Panel B: Contribution of changes in family and work characteristics to changes in living standards of poor children in single-parent families

Market income

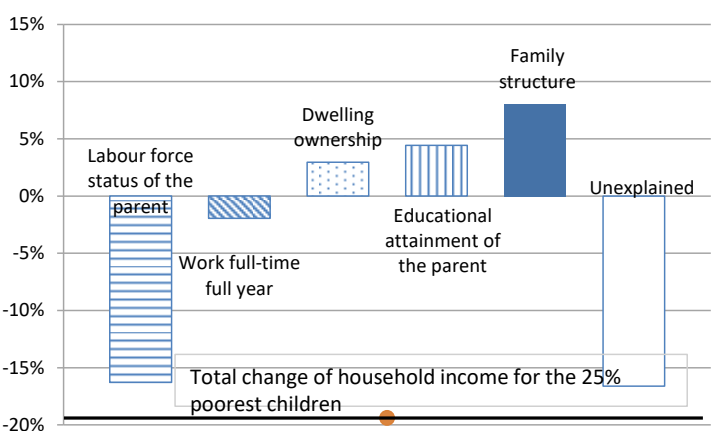

Disposable income

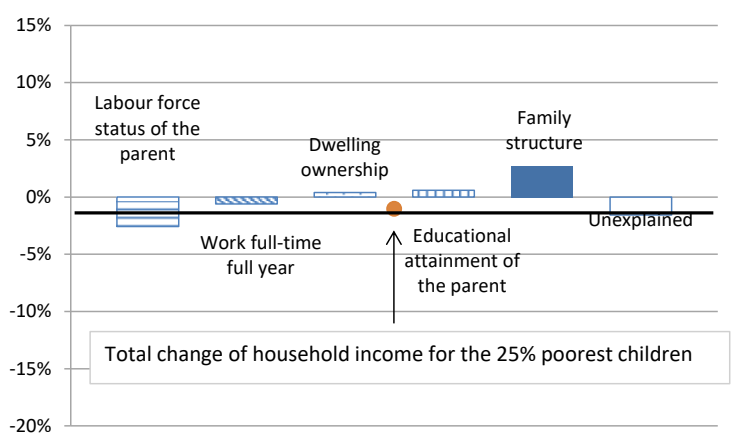

Note: Market income is the sum of: wages and salaries, net self-employment net income, interest and investment income, private pension and registered retirement savings plan income, and includes alimony or support income received, and other income; Disposable income is total income less: income tax, employment insurance contributions, public and private pension plan contributions, union dues (incl. professional membership dues, and malpractice liability insurance premiums), childcare expenses incurred in order to hold a paid job, alimony or support payments paid, and public health insurance premiums. Household income is equivalised using the square root scale. The term 'standard of living' refers to the equivalised disposable income.

Family structure includes information on the number of children, age of children and parents, and possible presence of other adults.

The black line shows the total percentage change in the household income from 2007 to 2014 for the $25^{\text {th }}$ percentile of children at the bottom of the income distribution in respectively two-parent (Panel A) and single-parent (Panel B) families. Each bar reflects the contribution of changes in family and work characteristics to the evolution of income, and the last white bar shows the percentage change of the income quantile that is not explained by changes in any of the observed household characteristics. The contribution is positive (resp. negative) when changes in given characteristics contributed to raise (resp. decrease) the income threshold of poor families. For instance, market income of "poor" children in two-parent families increased by 3\% in two-parent families from 2007 to 2014; change in educational attainment of parents in these families tended to raise the family income threshold of the poorest $25 \%$ children by almost $4 \%$, but this effect was offset by the negative effects mainly related to changes in housing status $(-3 \%)$ and fathers' employment status $(-1.1 \%)$. Much of the increase in market income is not explained by changes in observed household characteristics. This unexplained share is as large as the contribution of the change in parental education level. The contributions of each characteristic to income changes are ranked from most negative to most positive.

Source: OECD Estimates based on the 2007 Survey on Labour and Income Dynamics and the 2014 Canadian Income Survey. 
26. The situation of children in single parent families differs strongly from those of children in two-parent families: they experienced a substantial loss of market income that is particularly sharp (-19\%) for families with the lowest incomes (Figure 3, Panel B). This decline is primarily due to the reduced employment participation among single parents: $24 \%$ of children in a single-parent family had a parent working full time in 2014, compared with almost $40 \%$ in 2007 .

27. The structure of single parent families is also changing: compared to 2007 singleparent families in 2014 were smaller and were more 6 percentage points likely to have only one child (36\%in 2014 and 31\% in 2007). This increases opportunities for single parents to look for work and thus has a positive effect on market gains.

28. In Canada, social transfers have played an important role for single-parent families to counterbalance the drop in earnings between 2007 and 2014, but outcomes vary across the income distribution (Annex B): as shown in Figure 3 Panel B, the disposable income of the $25 \%$ of children in single-parent families at the bottom of the income distribution was relatively stable, while it increased for children in higher-income single-parent families, despite a decrease in market income (see Annex B). In other words, while social transfers have barely compensated for market income losses in the lower end of income distribution, they have contributed to a rise in living standards for wealthier single-parent families who benefit from higher tax deductions. The gap in the standard of living between the poorest and the wealthiest children in single-parent families is widening, as is the gap between children in single and two-parent families.

29. In all, children in single-parent families were most affected by the drop in employment rates of their parents since 2007, which led to a particularly marked drop in income at the bottom of the income distribution. Social transfers have largely cushioned the decline in market incomes, but income disparities in living standards among single-parent families have increased significantly. The poverty rate among unemployed single-parent families is also particularly high in Canada compared to the OECD average. Promoting the employability, return and job retention of these parents should therefore be one of the priorities for action for these populations to combat child poverty.

30. Moreover, risk factors for child poverty have changed since 2007 for children with two parents and/or single-parent families. First, a growing proportion of poor children have parents with higher education degrees, because more parents in aggregate now have higher education degrees. As a consequence, the risk of poverty spreads among the most educated parents, while at the same time higher education can improve families' standard of living. The reform of child benefits in 2016 reduces this risk by granting a more targeted benefit to a large proportion of families. Other complementary measures could accompany this reform to encourage employment, facilitate the integration of parents seeking work into the labour market, increase work intensity and promote the reconciliation of work and family life. 


\section{Patterns of children's material deprivation}

31. Poverty can contribute to material deprivation and the Canadian Survey on Economic Well-Being facilitates extending the analysis to consider the prevalence and nature of material deprivation experienced by families with children. One limitation of this survey (compared for example to some existing surveys in Europe) is that the questions asked to households do not specifically pertain to children. In the analysis that follows, children are considered "victims" of deprivation when the survey respondent has answered that at least one family member are unable or do not have access to the goods or activities in question. However, it is possible that within a family categorized as experiencing deprivation, children will not be victims if, for example, parents have their children's needs met as a priority.

32. Unlike European surveys, the Canadian survey also does not provide information on the availability of resources to meet children's specific educational, recreational or sportrelated needs.

33. Material deprivation is not limited just to families living in income poverty - children in non-poor households can grow up without access to essential goods and opportunities, too - but the risks of deprivation are generally much higher among income-poor families than among the non-income-poor. Table 2 shows the share of children under 17 in Canada deprived of a range of material goods, resources and opportunities grouped according to their income poverty status. Non-income-poor children are less likely than income-poor children to be deprived on all of the measures in Table 2. For instance, around 5\% of non-income poor children experience housing issues - a composite measure that captures whether or not the home is overcrowded, able to be kept adequately warm and free of unwanted pest - but their proportion is more than three times as high among the income poor $(16 \%)$. About $7 \%$ of income poor children have difficulty keeping their housing at a comfortable temperature, while the proportion is less than $2 \%$ among non-poor children.

34. A significant gap also concerns the use of dental care: less than $7 \%$ of non-income poor children but nearly one third of poor are in a family who give up dental care. Noticeable differences also concern food deprivation, with one in six income poor children live in a family reporting nutrition deprivation compared to one in twenty non-poor children. A similar gap exists also in the risk of food deprivation. More than one in ten income-poor children $(11.6 \%)$ do not eat fruit or vegetables every day, which is three times higher than the non-income poor, and more than $8 \%$ do not eat meat or equivalent at least once a day, which is 4 times higher than for the non-income poor children. Poor children are five times more likely than non-poor to be unable to replace worn clothing.

35. Access to leisure activities also differs according to income level: more than $31 \%$ of poor children are in a family reporting that at least one member has no regular leisure activity while they are only $10 \%$ among non-income poor families. $9.4 \%$ of income poor children are in a family with no internet access at home, while only $2 \%$ of non-income poor children are in this situation.

36. In all, 6 in 10 income poor children in Canada lack access to at least one item or opportunity, compared to $22 \%$ among the income non-poor; and $8 \%$ experience "severe deprivation" because they are deprived in at least four of the dimensions considered in Table 2. Finally, it is not surprising to see that $53 \%$ of income poor children live in a family that has difficulty making ends meet, whereas less than one in five of children in non-poor families do. 
Table 2. Material deprivation rates according to the diverse dimensions Canada 2013

Percentage of children reporting material deprivation

\begin{tabular}{lccc}
\hline \multicolumn{1}{c}{ Non income-poor } & Income-poor & Total \\
Housing & $5.2 \%$ & $15.9 \%$ & $7.2 \%$ \\
Keep dwelling free of unwanted pests & $3.5 \%$ & $5 \%$ \\
Keep dwelling at comfortable temperature & $11.0 \%$ & \\
& $1,9 \%$ & & $2,9 \%$ \\
\hline Dentist & 6.5 & $6.8 \%$ & 11.4 \\
\hline Nutrition & $5.5 \%$ & 32 & $7.6 \%$ \\
Fruits and vegetables at least once a day & $3.5 \%$ & $16.4 \%$ & $5 \%$ \\
\hline Meat, chicken or equivalent at least once a day & $11.0 \%$ & $3.4 \%$ \\
\hline Clothing & $2.1 \%$ & $8.4 \%$ & $4.2 \%$ \\
\hline Leisure & $2.3 \%$ & $12.0 \%$ & $14.6 \%$ \\
\hline Internet & 10.7 & 31.2 & $3.5 \%$ \\
\hline Any deprivation & 2 & 9.4 & $29.7 \%$ \\
\hline Severe deprivation & $22.3 \%$ & $60.8 \%$ & $2.4 \%$ \\
\hline Difficulty meeting expenses (including housing) & 18.4 & $7.8 \%$ & 25.1 \\
\hline
\end{tabular}

Source: Canadian Survey of Economic Well-Being, 2013. See Annex B for details about the variables.

37. A key question for developing appropriate policies is to identify not only which forms of deprivation are most common, but also to what extent some children accumulate, combine, and suffer from multiple types of deprivation all at the same time, as well as to identify the characteristics of their household that makes it more likely. To examine this, different groups of children are identified (by means of a Latent Class Analysis) among all income-poor children. 
38. Table 3 summarises the different groups that can be identified according to deprivation patterns. The available information suggests that:

- A very small minority of children in Canada (1.4\% representing more than 90,000 children) show deprivation in most of the different dimensions: all face deprivation in terms of clothing, 9 out of 10 in terms of nutrition and two-thirds have deprivation in terms of leisure activities. Almost 4 in 10 children in this group also experience housing problems.

- Nearly one in 10 children experience deprivation in dental care, but they also rather often cumulate other types of deprivation: half of children in this group live in households with no regular leisure activity, and a quarter experience deprivation in nutrition and/or housing.

- $30 \%$ of children are deprived either of leisure (31\%), nutrition (11\%) or housing $(10 \%)$.

Table 3. Groups of children at risk of material deprivation

\begin{tabular}{|c|c|c|c|c|}
\hline & ups as obtained $b$ & Latent Class analysis & & \\
\hline & $\begin{array}{l}\text { Group } 1 \\
\text { Generally deprived } \\
\text { children }\end{array}$ & $\begin{array}{c}\text { Group } 2 \\
\text { Families forgoing Dental } \\
\text { Care }\end{array}$ & $\begin{array}{c}\text { Group } 3 \\
\text { Leisure deprived } \\
\text { children }\end{array}$ & $\begin{array}{l}\text { Group } 4 \\
\text { Not deprived } \\
\text { children }\end{array}$ \\
\hline $\begin{array}{l}\text { Prevalence of the group (\% of income poor } \\
\text { children) }\end{array}$ & $1,4 \%$ & $9,1 \%$ & $29,4 \%$ & $60,1 \%$ \\
\hline \multicolumn{5}{|l|}{ INDICATOR } \\
\hline Clothing & $100,0 \%$ & $16,7 \%$ & $3,7 \%$ & $0,3 \%$ \\
\hline Nutrition & $91,0 \%$ & $25,9 \%$ & $11,5 \%$ & $1,0 \%$ \\
\hline Dental care & $31,1 \%$ & $100,0 \%$ & $0,0 \%$ & $3,3 \%$ \\
\hline Leisure activity & $67,2 \%$ & $50,9 \%$ & $30,8 \%$ & $0,0 \%$ \\
\hline Internet & $17,3 \%$ & $10,5 \%$ & $7,6 \%$ & $0,1 \%$ \\
\hline Housing & $39,0 \%$ & $23,6 \%$ & $10,2 \%$ & $2,6 \%$ \\
\hline
\end{tabular}

Source: Canadian Survey of Economic Well-Being, 2013.

39. Compared to the group of children who do not experience deprivation of any kind, children who are generally deprived (group 1) have a lower average income and are much more likely to be extremely poor: $72.1 \%$ belong to the first decile compared to $15 \%$ of nondeprived children (Table 4). These children also have a higher incidence of single-parent families: $42 \%$ of children in this group are headed by a single parent, while it is less than $9 \%$ in the group of not deprived children (group 4). Parents in this group are also significantly more likely to have a level of education attainment below tertiary level and are significantly more likely to be unemployed or jobless than other group: $26 \%$ of children in this group have jobless parents, against only $3 \%$ in the group of not deprived children (group 4 ).

40. With regard to the financial assistance received, generally deprived children show a higher coverage by cash benefits than other groups: more than 9 out of 10 heavily deprived children are in a family receiving child tax credit, but 1 out of 10 does not receive it. A much smaller proportion, one-third of children in this group, receives social assistance. 
41. For children in families deprived of dental care (Group 2), they also often have a very low-income (around 2/3 of children in the group belong to the first income decile), and their family is frequently headed by unemployed or jobless parents. This group also includes more families with a background migrant than others: $40 \%$ of children in this group have both parents born outside Canada. Finally, these children are less well covered by social assistance than children in the previous group, since about 1 in 5 children in this group are in a family who receives a social assistance allowance against one third in group 1.

Table 4. Characteristics of the groups of materially deprived children in Canada

\begin{tabular}{|c|c|c|c|c|c|}
\hline \multicolumn{6}{|l|}{ Prevalence of the group } \\
\hline & Group 1 & Group 2 & Group 3 & Group 4 & Total \\
\hline & $\begin{array}{c}\text { Generally } \\
\text { deprived families }\end{array}$ & $\begin{array}{l}\text { Families forgoing } \\
\text { Dental Care }\end{array}$ & $\begin{array}{l}\text { Leisure deprived } \\
\text { families }\end{array}$ & $\begin{array}{l}\text { Not deprived } \\
\text { families }\end{array}$ & \\
\hline average income & 21300 & 23700 & 40800 & 57600 & \\
\hline 1st decile & $72.1 \%$ & $64.3 \%$ & $33.5 \%$ & $15.0 \%$ & $22.6 \%$ \\
\hline 2nd decile & $19.9 \%$ & $23.6 \%$ & $22.0 \%$ & $20.1 \%$ & $20.7 \%$ \\
\hline \multicolumn{6}{|l|}{ Number of parents in household } \\
\hline 0 or 1 & $41.8 \%$ & $25.8 \%$ & $16 \%$ & $8.9 \%$ & $11.8 \%$ \\
\hline 2 & $58.2 \%$ & $74.2 \%$ & $84 \%$ & $91.1 \%$ & $88.2 \%$ \\
\hline \multicolumn{6}{|l|}{ Migration background } \\
\hline native background & $80.6 \%$ & $59.4 \%$ & $69.7 \%$ & $77.5 \%$ & $74.9 \%$ \\
\hline migrant background & $19.4 \%$ & $40.6 \%$ & $30.3 \%$ & $22.5 \%$ & $25.1 \%$ \\
\hline \multicolumn{6}{|l|}{ Number of children in household } \\
\hline 1 or 2 & $58.2 \%$ & $62.8 \%$ & $58.8 \%$ & $67.5 \%$ & $65.5 \%$ \\
\hline 3 and more & $41.8 \%$ & $37.2 \%$ & $41.2 \%$ & $32.5 \%$ & $34.5 \%$ \\
\hline \multicolumn{6}{|c|}{ Education level of mother (father if no mother } \\
\hline Below tertiary education & $93.5 \%$ & $74.7 \%$ & $73.3 \%$ & $60.3 \%$ & $64 \%$ \\
\hline Tertiary education & $6.5 \%$ & $25.3 \%$ & $26.7 \%$ & $39.7 \%$ & $36 \%$ \\
\hline \multicolumn{6}{|l|}{ Employment status of parents } \\
\hline Both parents unemployed & $26.7 \%$ & $21.1 \%$ & $11.5 \%$ & $3.7 \%$ & $6.7 \%$ \\
\hline At least one parent employed & $73.3 \%$ & $78.9 \%$ & $88.5 \%$ & $96.3 \%$ & $93.3 \%$ \\
\hline Jobless household & $25.9 \%$ & $19.2 \%$ & $10.2 \%$ & $2.9 \%$ & $5.7 \%$ \\
\hline At least one person employed & $74.1 \%$ & $80.8 \%$ & $89.8 \%$ & $97.1 \%$ & $94.3 \%$ \\
\hline \multicolumn{6}{|l|}{ urban environment } \\
\hline rural environment & $22.5 \%$ & $33.4 \%$ & $29.9 \%$ & $33.1 \%$ & $32.4 \%$ \\
\hline urban environment & $77.5 \%$ & $66.6 \%$ & $70.1 \%$ & $66.9 \%$ & $67.6 \%$ \\
\hline \multicolumn{6}{|l|}{ Benefits by categories } \\
\hline Child tax benefit receipt & $91.2 \%$ & $90.2 \%$ & $77.9 \%$ & $68.9 \%$ & $72.3 \%$ \\
\hline Social assistance receipt & $33.4 \%$ & $19.9 \%$ & $9.9 \%$ & $2.7 \%$ & $5.6 \%$ \\
\hline
\end{tabular}

Source: Canadian Survey of Economic Well-Being, 2013. 
42. To sum up, this analysis shows that although non-income poor families experience forms of deprivation, extreme monetary poverty is a factor aggravating the risk of experiencing multiple deprivations. Only a very small minority of children (about 90,000 children, i.e. $1.4 \%$ of all children aged 0 to 17) experience deprivation in all areas, but some of their characteristics (single parenthood, unemployment or joblessness, low parental education) make them more vulnerable than others. However, a larger group of children $(10 \%)$ leave in families that do not receive dental care that would be needed, and this is often combined with poor quality housing conditions and/or food or leisure deprivation. Very lowincomes, lack of employment and the presence of parents born outside Canada are factors putting children at a greater risk of facing multiple deprivations. Although the families of these two groups of children usually receive financial assistance (child tax credit, social assistance benefit), a significant minority of them still face multiple deprivations. These situations therefore show the need to strengthen the financial support of these families and to accompany this support in cash with assistance in terms of employment, medical and dental insurance to better cover medical costs, or measures to promote housing renovation to best address the multiple deprivations shown by these families. 


\section{Child Well-Being: How does Canada compare to other OECD countries?}

43. Information on the well-being of children in Canada is not as comprehensive as the information available for European countries. The data that are available on the OECD Child Well-Being Data Portal ${ }^{1}$ show a mixed picture (Figure 4).

44. At home, children in Canada enjoy higher average disposable incomes than their peers in many other OECD countries. At $15 \%$, the child income poverty rate is comparatively moderate and just slightly above the average for OECD countries (13.4\%).

45. Parent-child relationships seem comparatively good, with only $3.5 \%$ of 15 -year-olds in Canada reported not talking to their parents before or after school on the last day they went to school - much lower than in some other countries like Mexico or Turkey, for example, where around $10-11 \%$ of 15 -year-olds are in this situation.

46. Child health outcomes show mixed results. Infant mortality is above OECD average (4.8 deaths per 1,000 births, compared to 3.9 on average), and the low-weight birth rate is comparable to the OECD average (6.3\%, compared to an OECD average of $6.5 \%)$. The proportion of 15-year-olds engaging in intense physical activity is comparatively high (almost 59\%, versus an OECD average of 52.3\%), but overweight and obesity rates are also relatively high - almost $28 \%$ of $11-15$ year-olds in Canada are overweight or obese, compared to an OECD average of $19 \%$.

47. Not all children benefit from optimal conditions for studying: about $18 \%$ of 15 -yearolds in Canada do not have a desk and quiet place to study at home, $26 \%$ do not have books to help with school work, and $36 \%$ feel anxious about school tests even if well-prepared. Nevertheless, Canadian teenagers perform very well on the OECD's PISA reading and mathematics tests, and the proportion of 15 -year-olds who plan to pursue higher education is comparatively high.

48. About $6.3 \%$ of $15-19$ year olds in Canada are not in employment, education or training, slightly above the OECD average (6.0\%). The adolescent (15-19 year old) fertility rate is also near the average for OECD countries.

\footnotetext{
${ }^{1}$ The Child Well-Being Data Portal (CWBDP) gathers data on child well-being and the settings in which children grow up. It provides information on children's home and family environment, their health and safety, their education and school life, their activities and their life satisfaction, and also links to information on public policies for children. Information covers children from 0 to 17 years of age, although some information is available only for specific ages. Where possible, information is provided for different age groups, from early childhood to adolescence. The data portal also provides a unique source of information on disparities in child well-being by gender, family status, household income level, and parental background
} 
Figure 4. How Canada compares to other OECD countries on 19 key measures

\begin{tabular}{|l|l|}
\hline Average disposable household income for children \\
Children in relafive income poverty \\
\hline Adolescents talking to their parents before or afer school \\
\hline Infant health & Infant mortality \\
\hline Low-weight births \\
\hline Child and adolescent & Adolescents skipping either breakfast or dinner \\
\hline Adolescents regularly engaging in vigorous exercise
\end{tabular}

Note: Performance relative to other OECD countries with available data on each measure. For measures where a larger value is generally 'better' (e.g. 'adolescents reporting high life satisfaction'), 'high performer' (green circle) means a value greater than the OECD mean by more than half the OECD standard deviation (s.d.), and 'low performer' (red square) a value less than the OECD mean by more than half an s.d. For measures where a smaller value is better (e.g. 'adolescents reporting low life satisfaction'), 'high performer' means a value less than the OECD mean by more than half an s.d., and 'low performer' a value greater than the OECD mean by more than half an s.d. In both cases 'moderate performer' means a value within half an s.d. of the OECD mean. Source. OECD Child Well-Being Data Portal.

49. Unlike in most OECD countries, immigrant students in Canada perform better on average than non-immigrant students in all education and school life outcomes. There was a difference of 10 score points between non-immigrant and immigrant children in Canada in the PISA mathematics test (Figure 5). Similarly, immigrant students in Canada are more likely to expect to complete a university degree (Figure 6), with a difference of 19.72 percentage points, compared to the OECD average difference of -0.34 percentage points. However, regarding health outcomes, like in many OECD countries, immigrant students are less likely to engage in regular physical activity in Canada, with a difference of -7.02 percentage points compared to the OECD average difference of -3.66 percentage points. 
Figure 5. Mathematics performance at age 15 (PISA), by migrant status

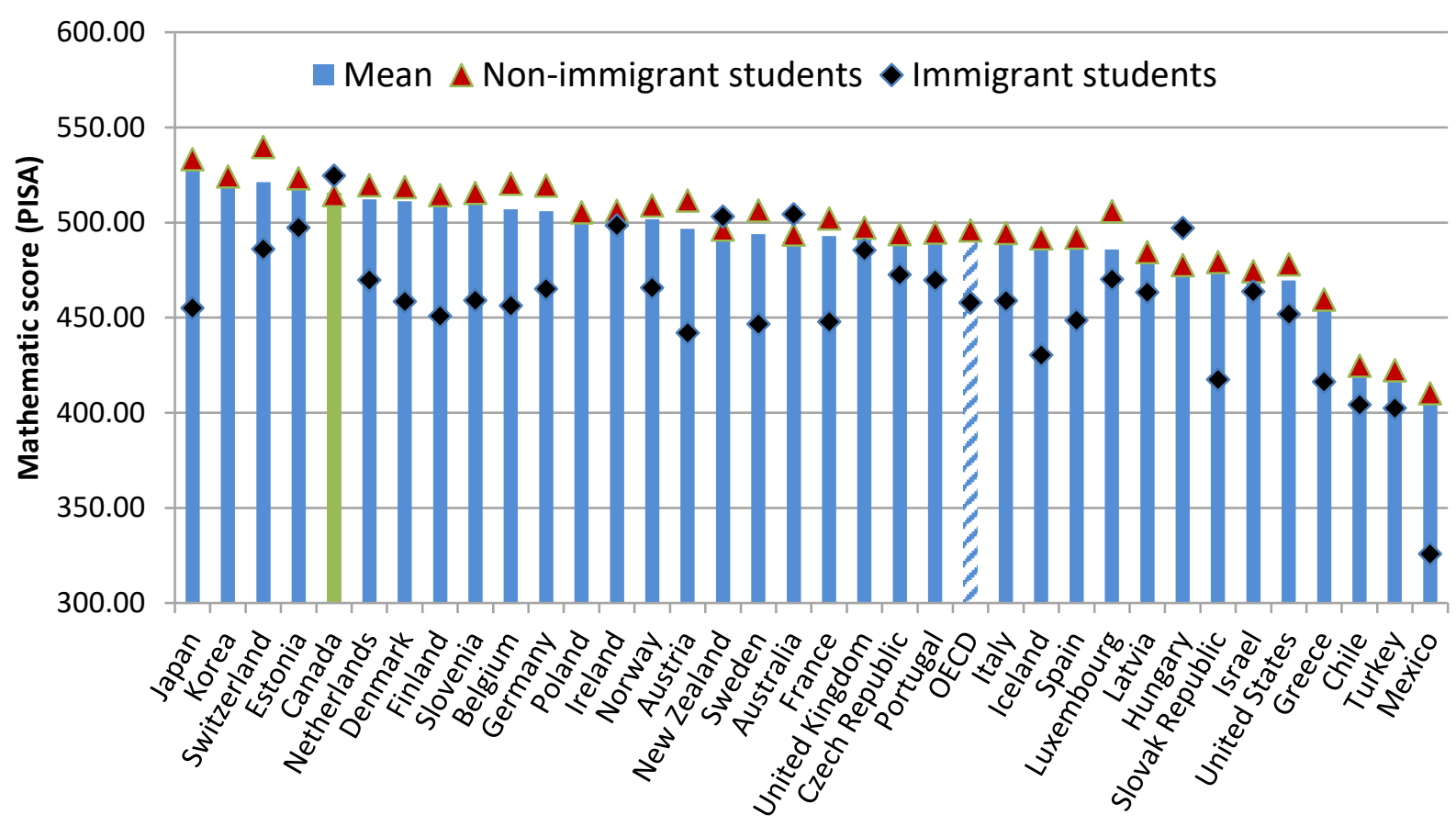

Source. PISA 2015. OECD Child Well-Being Data Portal.

Figure 6. Adolescents who expect to complete a university degree, by migrant status

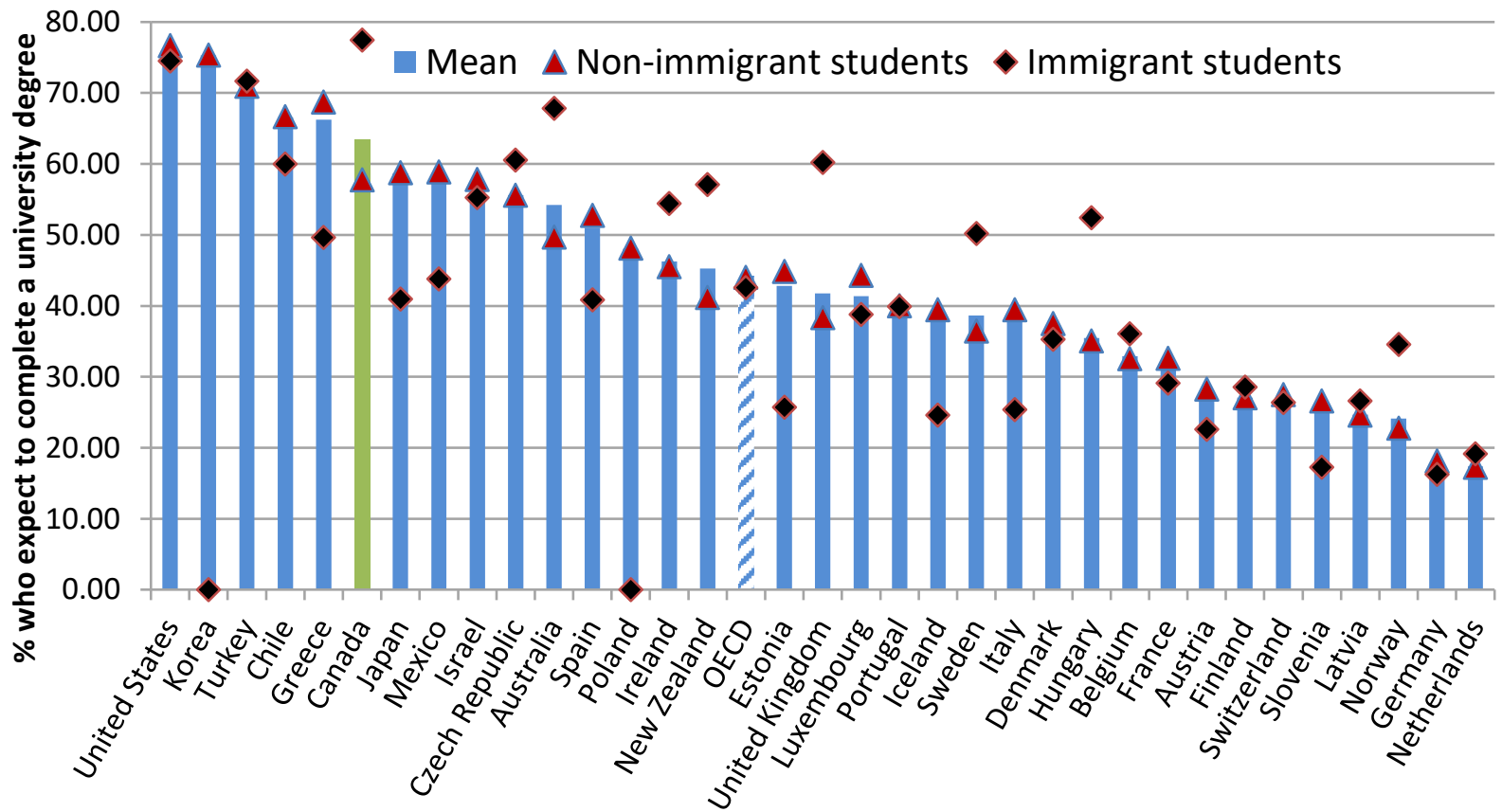

Source. PISA 2015. OECD Child Well-Being Data Portal. 
50. Similar to other OECD countries there are large differences in education and school life outcomes in Canada on the basis of socio-economic status, measured by the Index of Economic, Social and Cultural Status (ESCS) and by the Family Affluence Scale (FAS). Canada has differences on the ESCS scale that are higher than average for access to a desk and a quiet place to study, as well as access to books for school work (Figure 7). 59.25\% of children have access to books for school work in the lowest quartile, which is 30.97 p.p. lower than the highest quartile, compared to an OECD average difference of 21.81 p.p.. Canadian students from the lowest quartile are also less likely to feel like they belong in school, where $64.72 \%$ of children said that they belonged, a difference of 14.98 p.p. with the highest quartile, compared with an OECD average difference of 7.72 p.p.

Figure 7. Adolescents with books for school work at home, by ESCS quartile

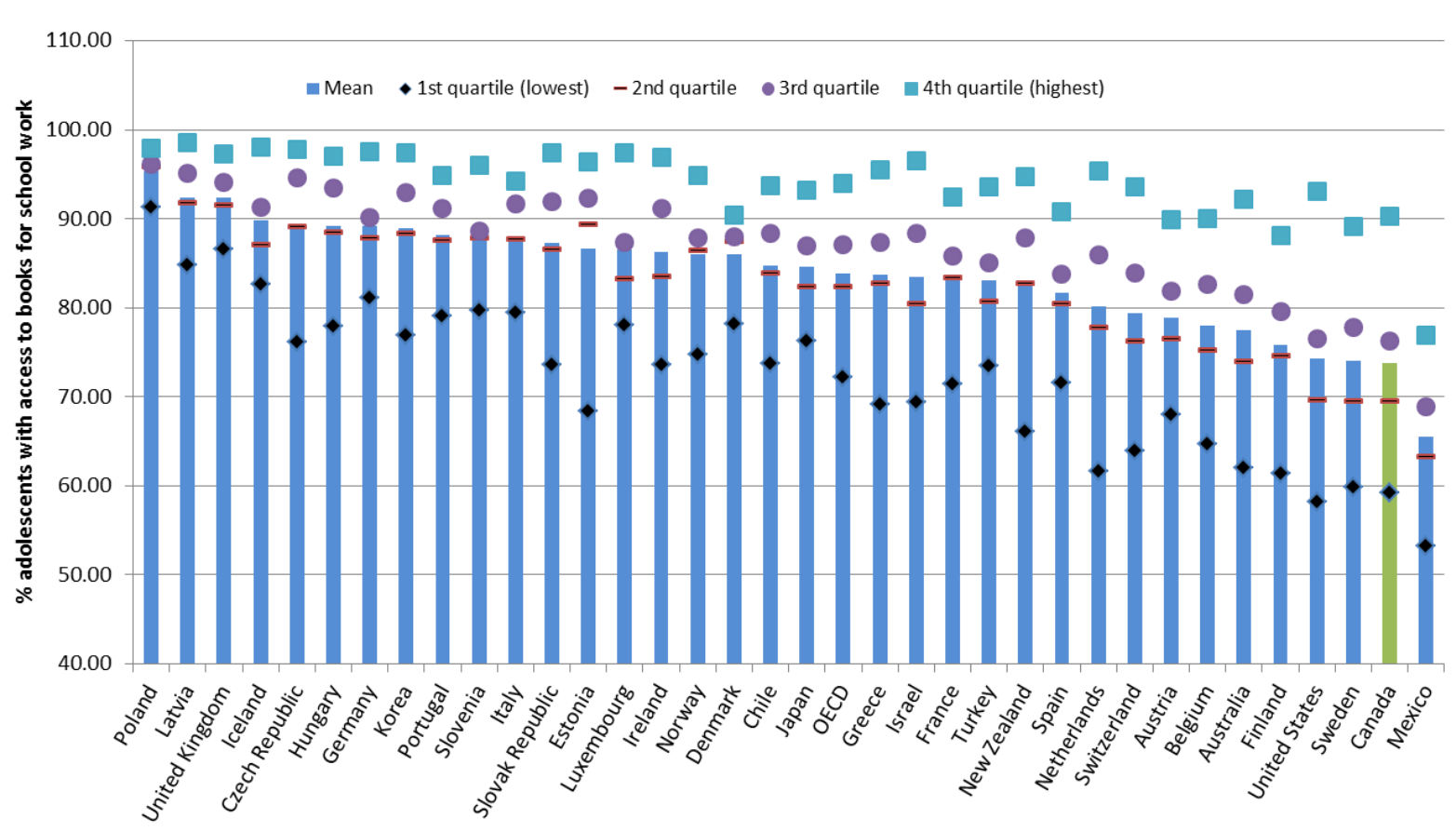

Note: Quintiles based on the Index of Economic, Social and Cultural Status (ESCS)

Source. PISA 2015. OECD Child Well-Being Data Portal.

Similarly, there are large differences in health outcomes on the basis of socio-economic status like many other OECD countries, but Canada has differences above the OECD average. $4.75 \%$ of Canadian students from the lowest FAS quintile are regular smokers and this is 3.85 p.p. more than the highest quintile, above the OECD average difference of 0.99 p.p (Figure 8). 
Figure 8. Children who are regular smokers

Percent of 11-, 13- and 15-year-olds who smoke at least once a week.

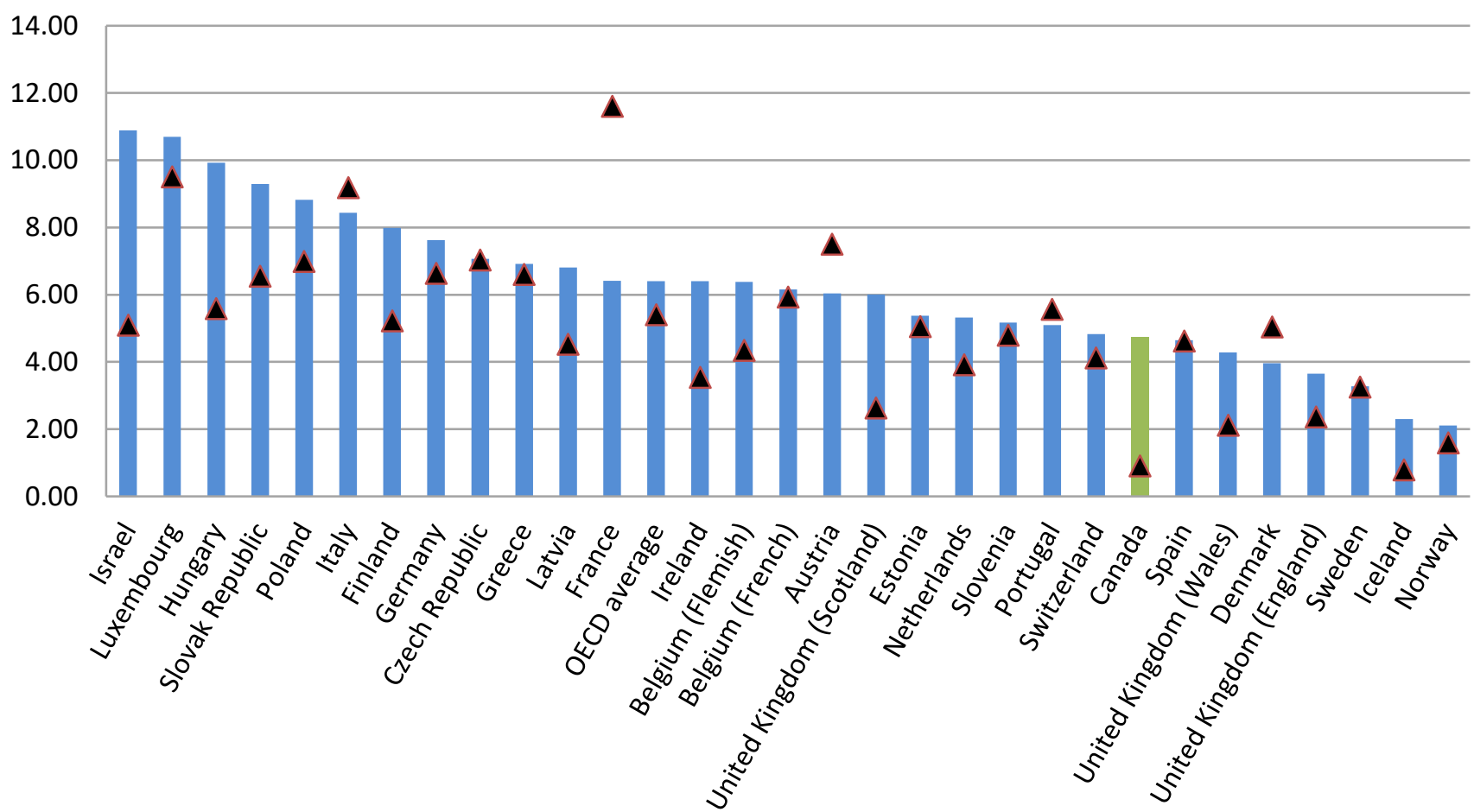

Note: The HBSC Family Affluence Scale (FAS) is a composite measure used to estimate a student's socioeconomic background. The composite is derived from several measures of common material assets or activities: the presence and number of cars, vans and trucks owned by the family; the presence and number of computers owned by the family; the presence of a dishwasher in the child's home; the presence and number of bathrooms in the child's home; whether or not the child has their own bedroom'; and the number of times in the previous year the child and their family travelled outside of the country/region of residence for a holiday/vacation. Responses are scored and summed to form the Family Affluence Scale (FAS). Here, children are divided into three groups according to their position in the distribution of FAS scores in their country or region:

Source: Health Behaviour in School-aged Children (HBSC) World Health Organization Collaborative CrossNational Survey 2013-14; OECD Child Well-Being Data Portal.

51. Like in many OECD countries, in Canada, parents' education level affects many child-wellbeing outcomes. $26.19 \%$ of Canadian students of low-educated parents were victims of bullying (Figure 9), which is 6.62 p.p. more than children of high-educated parents, and above the OECD average difference of 2.53 p.p. 
Figure 9. Adolescents who report being the victims of bullying, by education of parents

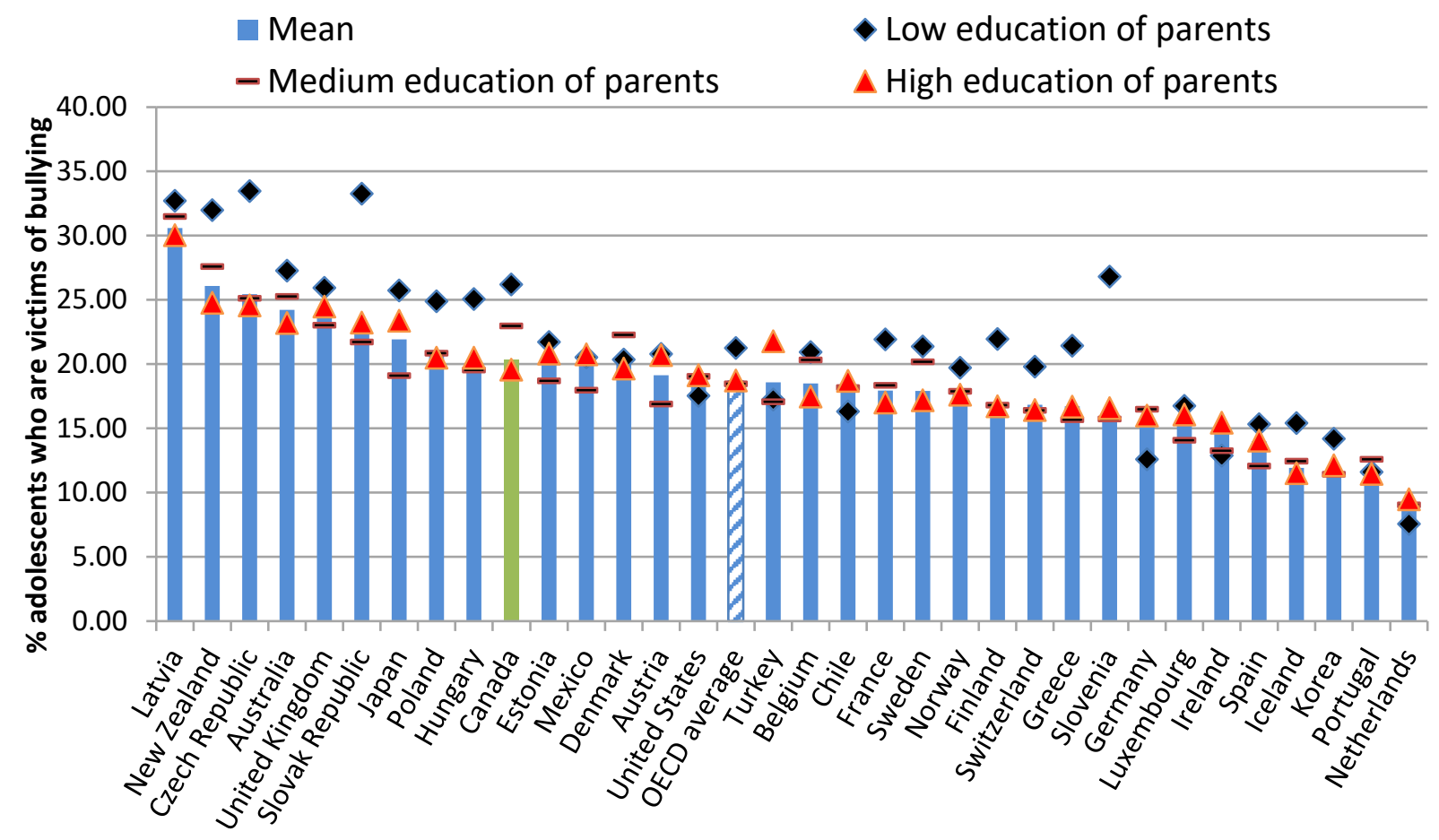

Source. PISA 2015. OECD Child Well-Being Data Portal.

52. When it comes to physical activity, gender differences for Canada are largely similar to the OECD average. Females are less likely to engage in vigorous exercise (Figure 10) in every OECD country, with an OECD average difference of -16.58 p.p., versus a Canadian difference of -15.73 p.p.. Females are less likely to be overweight or obese, with an OECD average difference of -3.92 p.p.. Canada also has no significant differences by gender for children who are regular smokers. 
Figure 10. Adolescents regularly engaging in vigorous exercise, by gender

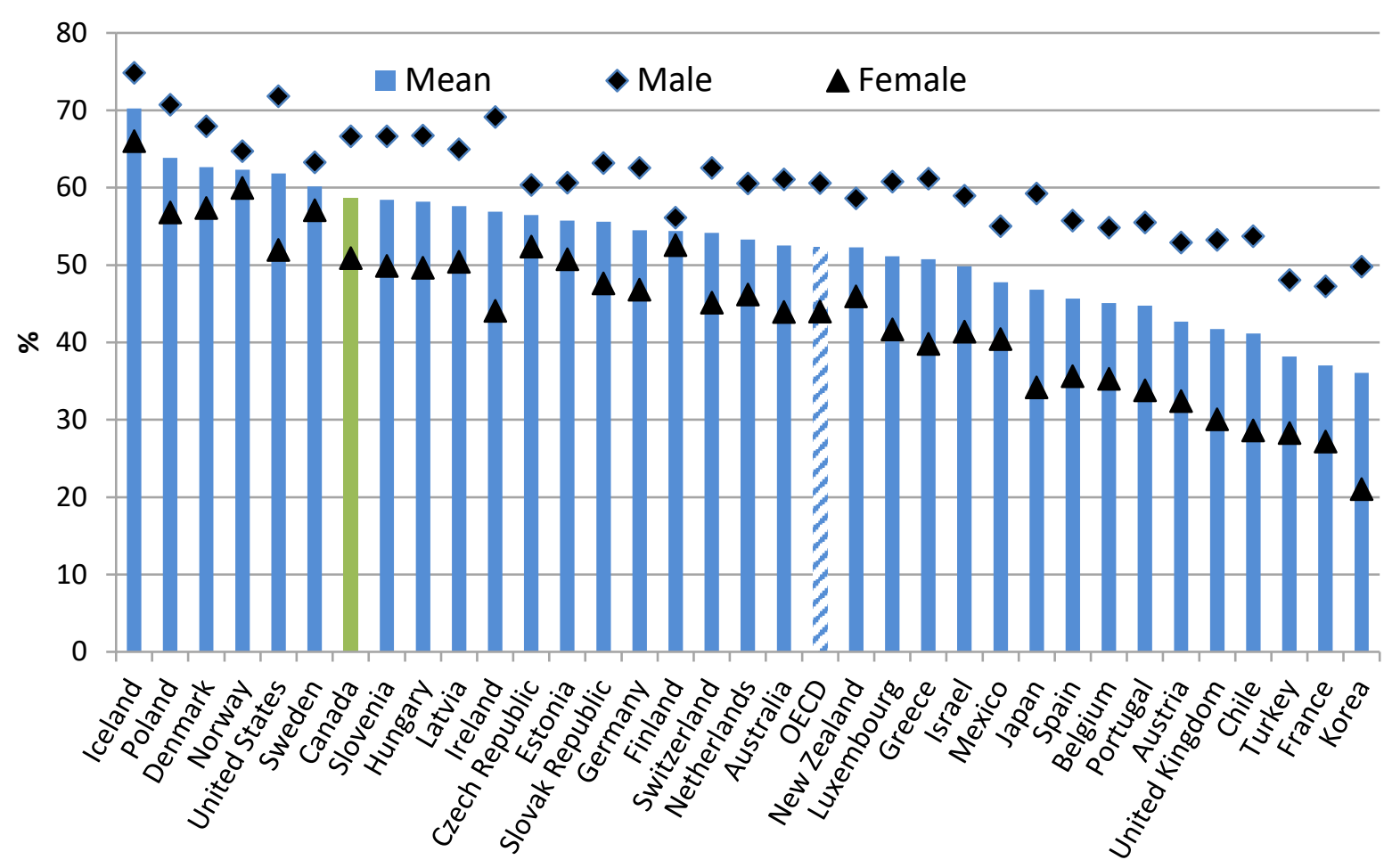

Source. PISA 2015. OECD Child Well-Being Data Portal. 


\section{Policy context}

53. Canada has long recognised the importance of reducing child poverty. Successive governments have implemented policies and programs aimed at supporting families with children sometimes building in progressive adjustments to increase allocations for families with low or modest incomes. In November 1989, for instance, the House of Commons adopted a unanimous all-party resolution to strive to eliminate poverty among Canadian children by the year 2000. This commitment has been reiterated with the aim to put in place a long-term investment plan to allow poor families to break out of the welfare trap so that children born into poverty do not carry the consequences of that poverty throughout their lives (Lefebvre and Merrigan, 2003 ${ }_{[9]}$ ). Over the course of several decades, different measures have been adopted by federal and sub-national government authorities to support families and to create an environment conducive to better opportunities for children.

54. Financial assistance contributes to significantly reducing child poverty, even before the adoption of recent measures to strengthen their impact. In 2015, redistributive transfers reduce child poverty by about 7.5 percentage points, which is the same magnitude as the OECD average.

Figure 11. Child poverty before and after tax and transfers

Percentage of children aged 0-17 in households with an equivalised income below $50 \%$ the median income, 2015.

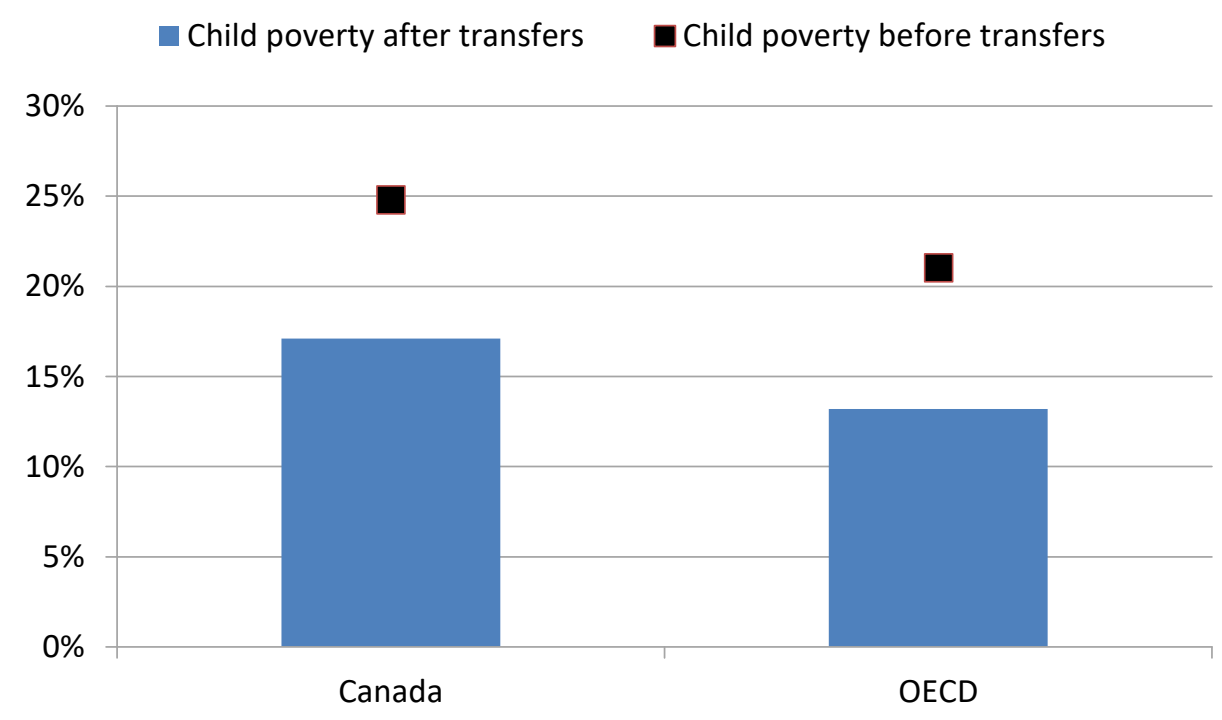

Source: OECD Income Distribution Database. 
55. At present, the main federal government policies and investments that aim to support families and/or reduce poverty include:

- The Canada Child Benefit (CCB) is a non-taxable progressive benefit that provides families with up to CAD 6,400 per child per year. It is projected that the CCB will help lift about 300,000 children out of poverty compared to before the reform (see Annex A for details). The Government proposes to strengthen the CCB by increasing the benefits annually to keep pace with the rising cost of living as of July 2018.

- The Working Income Tax Benefit is a tax measure aimed at making work pay for lowincome workers so they can keep more of their pre-tax income. For 2019 and subsequent taxation years, the government has proposed to introduce the Canada Workers Benefit (CWB), an enhanced version of the Working Income Tax Benefit (WITB). Compared to the WITB, the amount of the basic benefit will be increased, and the threshold from which the benefit phases out will be increased.

- The Employment Insurance Program (EI) is a taxable income replacement program that aims to support eligible workers through life transitions and different kinds of benefits that include unemployment benefits, maternity and parental leave benefits, sickness benefits, and caregiving benefits. Workers qualify for various EI benefits when they meet eligibility criteria related to labour market participation and life circumstances. The Family Supplement provides a modest top-up of benefits for lower income recipients with children.

56. The federal government works with provincial and territorial governments to address cross-cutting issues that are of shared jurisdiction including social development objectives. Agreements between orders of government to transfer funds for specific purposes are negotiated in a wide range of domains including: healthcare, workforce development, and early childhood education and care. Typically, provinces and territories are charged with the task of implementing programs that address specific social policy issues and reporting back on results and policy impacts. Federal grants and contributions programs such as the Homelessness Partnership Strategy provide resources to community groups to support initiatives that reduce homelessness.

57. Recently, the government has launched the development of a Canadian Poverty Reduction Strategy and a National Housing Strategy in view of reducing poverty and improving housing in Canada. The lack of affordable housing create serious challenges for low-income households, particularly those living in the major cities that have seen the greatest increases in house prices and rents. The National Housing Strategy, launched in November 2017, provides 40 billion over 10 years to construct 100000 new housing units, renovate 300000 existing units, enhance rental-construction financing and provide housing allowances to needy households (OECD, 2018 $\left.{ }_{[8]}\right)$. This Strategy is projected to help up to 530000 Canadians but the construction of new units under the plan will be insufficient to eliminate waiting list and inequity between those with access to social housing and those without will remain $\left(\mathrm{OECD}, 2018_{[8]}\right)$. Prioritising placement of applicant with the greatest needs is then necessary apart from priorities given, for example, to victims of domestic violence and beyond the principle of first-come first-served.

58. In August 2018, Government of Canada launched first Poverty Reduction Strategy to fight against poverty on multiple fronts (Employment and Social Development Canada, $\left.2018_{[2]}\right)$. This initiative introduces an official measure of poverty, and concrete poverty reduction targets to reduce the poverty rate by 20 percent from its 2015 level by 2020 and by 50 percent by 2030. It also established a National Advisory Council on Poverty to advise the 
Minister of Families, Children and Social Development on poverty reduction and to publicly report, in each year, on the progress made towards poverty reduction. Progress will be tracked not only by measuring the poverty rate based on Canada's Official Poverty Line, but also by using a dashboard of other indicators including measures of basic needs coverage, poverty intensity and poverty entry and exit rates.

59. The poverty reduction strategy has three objectives. The first is to enable individuals to live in dignity by ensuring that their basic needs (in terms of food, health, housing and income) are met. The second objective is to foster an inclusive society by helping Canadians join the middle class through measures to promote the development of the skills of vulnerable populations (such as young people or indigenous populations), access to quality employment and the development of early childcare services. The third objective is to support the middle class by protecting Canadians from falling into poverty and by supporting income security and resilience.

60. The reduction of child poverty could be identified as a specific objective of the recently launched poverty reduction strategy. The development of measures of children's exposure to income poverty and of unmet needs in terms of food, health, education and housing met would make it possible to set targets for children and monitor progress for this particular population group.

\subsection{Advancing Family Policies}

61. Several measures can be considered to protect children from the risk of poverty:

- Financial measures accompanying the reform of the Canada Child Benefit could capitalise on this positive trend by targeting supplementary measures to encourage more parents to enter the labour market by increasing the income gains associated with the return to employment. These measures could first target families with two parents whose 2015 effective tax rate related to the transition from inactivity to fulltime low wage employment is well above the OECD average (Annex A). In this respect, significant progress has been made for single-parent families since 2007, where effective tax rates linked to a shift to full-time employment are lower than the OECD average.

- The net cost of childcare in Canada (Ontario) is among the highest in the OECD (Figure 12). Efforts to increase the supply and improve the affordability of childcare are a longstanding policy priority, but have had mixed results. The supply of childcare spaces remains limited since it covers about a quarter of children aged 0 to 5 years, and a smaller proportion of the youngest in this age group (Friendly et al., $\left.2015_{[10]}\right)$. Moreover, regulated services are often unaffordable (MacDonald and Friendly, 2016[11]); long wait lists and hefty surcharges keep many children out (MacDonald and Friendly, 2016[11]), and the gender employment gap is higher in provinces with the highest cost of median childcare (Moyser, 2017 [12]). 
Figure 12. Out of pocket costs of childcare for low earner families

Net childcare costs for couple and single parent families, 2015.

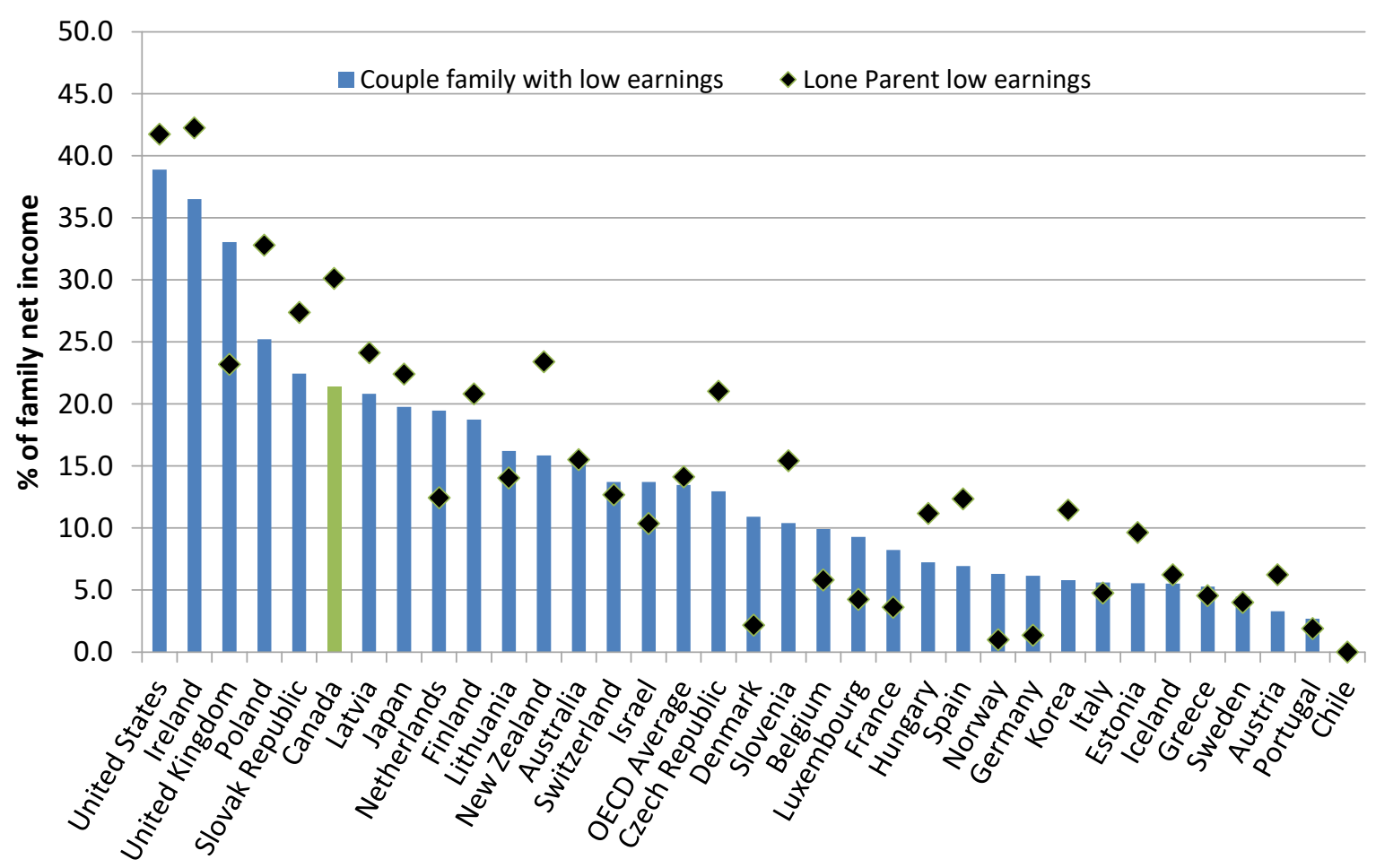

Note: 'Low' earnings level is 20th percentile of gender-specific full-time earnings distribution. Two earners are assumed for couples, male and female. In all cases, family has two children aged 3 and 2 using full-time centrebased care. Fees and, in some cases, public support measures do also vary across regions or municipalities in some countries. For Canada, fees and regulations as applying in Ontario is taken into account.

Source: Browne and Neumann (2017), OECD Tax Wedge and Effective Tax Rates on Labour - Child Care Costs in 2015.

62. Greater responsiveness of childcare policies could help parents deal when no affordable childcare solution is available upon the end of parental leave and/or if family circumstances have changed since the decision to take leave was taken (due to either the loss of a spouse's job or the separation of parents). The responsiveness can be ensured first of all by the adoption of clear and transparent rules concerning the allocation of places in childcare services for young children primarily to single-parent families and/or with a parent looking for work.

63. Greater responsiveness could be also achieved by allowing more flexible use of leave entitlements. For instance, some parents may have access to part-time childcare, for which a part-time leave could be a better solution for their constraints. The "Working while on claim" pilot project offers employment insurance beneficiaries a certain flexibility by allowing them to combine, up to a certain point, this insurance income with that obtained by taking over an activity (see details in Annex A). The evaluation and continuation of this scheme is an option that can encourage a return to employment with some flexibility.

64. Parental leave reform introduced in December 2017 gives eligible parents the opportunity to choose between the current 35 weeks of paid parental leave and a longer, (61 
week) period paid at a lower rate. The reduced level of income support and the prolonged period out of work may weaken labour force attachment, and can exacerbate the risk of poverty that already weighs on low-income families, especially single-parent families (Annex A). A higher remuneration rate for low-income families, capped at a certain level of earnings along with access to quality affordable childcare options could help better protect these families from the risk of poverty.

65. The responsiveness of childcare policies can finally be strengthened by adapting to the changing profiles of poor families, and in particular to the fact that poor single-parent families increasingly include a school-age child and/or young adolescent. Access to afterschool care services is therefore crucial for these families, not only to enable parents to reconcile their work and family life, but also to ensure that the children of these families have access to recreational facilities, as single-parent families often struggle to meet their children's recreational needs (Russel, Harris and Gockel, 2008 ${ }_{[13]}$ ).

66. Housing policy in Canada should prioritise support for poor families who rent their homes, since the proportion of children living in rental homes has risen sharply in recent years, and these families now are poorer relative to owner-occupied families than they were in the past. The sharp rise in house prices has squeezed low-income families out of home ownership, and is exposing them to rising rents. The preservation of social housing stock is an option that can address shortage of affordable housing, while rent control policies implemented in some provinces appear not to have the expected rent moderation effect and may discourage the supply of new housing (Andrews, Caldera Sánchez and Johansson, $\left.2011_{[14]}\right)$ (Oecd, 2017 $7_{[15]}$ ). The success of the National Housing Strategy will be measured in part by its impacts in poverty alleviation ${ }^{2}$.

67. The high proportion (32\%) of poor children in income living in households without dental care suggest that increased efforts can be made to strengthen access to dental care for poor households through existing programs led by the provinces and territories (Guttmann, A., Gandhi, S., Hanvey, Li, P., Barwick et al., 2017 [16]).

68. Lastly, urgent action is needed to support Indigenous children and families living in poverty who are two to three times more likely to be poor than the rest of the child population. First Nations' governments could be encouraged, with control over relevant resources, to formulate effective poverty reduction programs for their communities or actualise plans that have already been formulated. Providing high quality, culturally responsive ECEC to Indigenous children is an effective lever to improve education outcomes amongst Indigenous children (OECD, 2017 $\left.7_{[17]}\right)$.

\subsection{Better performance indicators for more effective policies}

69. Beyond specific measures, initiatives to improve the quality of the information available on poor families, their characteristics, and access to services such as childcare are key to ensure the effectiveness of the Poverty Reduction Strategy implemented by the Canadian government and to monitor progress. Furthermore, information is need on how poverty interacts with exposure to material deprivation, such as a lack of access to quality

\footnotetext{
${ }^{2}$ The Government of Canada recently announced a 10-year, \$40-billion National Housing Strategy to help ensure that Canadians have access to housing that meets their needs. Part of this strategy is a $\$ 4$ billion Canada Housing Benefit to be launched in 2020, a new tool to fight the challenge of housing affordability for vulnerable Canadians.
} 
nutrition and education materials to get a better view of the standard of living of Canadian children.

70. The development of Early Childhood Education and Care (ECEC) services is a key element in the fight against poverty. However, information available on childcare quality and its uses remains rather limited. Better information-sharing and co-ordination among provincial and federal authorities can improve the effectiveness of ECEC-policy Building reporting requirements into federal and provincial bilateral agreements for the development of ECEC and other social services would enable governments to tailor services and benefits to the needs of families

71. Information on material deprivation among children is limited. Nation-wide surveys on household material well-being are not conducted regularly and existing surveys do not include accurate information on material deprivation. Having more detailed information on the types of deprivation affecting children and the socio-demographic profile of their families is needed to better define and prioritise policy measures.

\subsection{Delivering in-cash and in-kind support}

72. The higher risk of experiencing severe and often multiple material deprivation among income poor families compared to the non-poor shows that it is necessary to supplement financial support with in-kind aid to reach the most disadvantaged families. Families with very low-incomes and jobless parents in particular are at greater risk of living in low-quality housing and experiencing deprivation in terms of food and/or dental care. For this group, getting out of poverty and its consequences effectively presupposes that barriers to employment are addressed, as well as obstacles that may limit access to care, to quality housing in addition to the financial aid that can be granted. For this, coordination between employment, health, housing or social services is necessary, which can be ensured, for example, by a management on a case-by-case basis and the implementation of a communitybased single-entry point to services (OECD, 2015 $[18])$. 
References

Abkari, E. and K. MacCuaig (2018), Early Childhood Education Report 2017, Atkinson Centre for Society and Child Development - University of Ontario, http://ecereport.ca/media/uploads/2017-report-pdfs/ece-report2017-en-feb6.pdf (accessed on 04 September 2018).

Aboriginal Children in Care Working Group (2015), Aboriginal Children in Care: Report to Canada's Premiers, http://canadaspremiers.ca/wpcontent/uploads/2015/07/aboriginal_children_in_care_report_july2015.pdf (accessed on 29 November 2017).

Akbari, A. and K. McCuaig (2014), Early Childhood Education, Ontario Institute for Studies in Education., Toronto.

Andrews, D., A. Caldera Sánchez and Å. Johansson (2011), "Housing Markets and Structural Policies in OECD Countries", OECD Economics Department Working Papers, No. 836, OECD Publishing, Paris, http://dx.doi.org/10.1787/5kgk8t2k9vf3-en.

Battle, K. (2015), “Child Benefits in Canada: Politics versus Policy”, Renewing Canada's Social Architecture, Caledon Institute of Social Policy.

Canada Mortgage and Housing Corporation (2017), Rental Market Report: Canada Highlights, Canada Mortgage nad Housing Corporation.

Cleveland, G. (2015), ECEC Policy in Canada: Availability, affordability and quality, Canadian Center for Policy Alternatives, https://www.google.com/search?q=cleveland+2015+childcare+canada\&sourceid=ie7\&rls=com. microsoft:fr-FR:IE-Address\&ie=\&oe=\&gws $r d=$ ssl.

Department of Finance (2017), Backgrounder: Strengthening the Canada Child Benefit, Department of Finance, https://www.fin.gc.ca/n17/data/17-103 1-eng.asp.

Employment and Social Development Canada (2018), Opportunity for All: Canada's First Poverty Reduction Strategy, Employment and Social Development Canada, Toronto, https://www.canada.ca/en/employment-social-development/news/2018/08/backgrounderopportunity-for-all--canadas-first-poverty-reduction-strategy.html.

Employment and Social Development Canada (2017), 2016-2017 Departmental Results Report, https://www.canada.ca/en/employment-social-development/corporate/reports/departmentalresults/2016-2017.html (accessed on 29 November 2017).

Friendly, M. et al. (2015), Early Childhood Education and Care in Canada 2014, Childcare Resource and Research Unit, http://childcarecanada.org/sites/default/files/ECEC-2014-fulldocument-revised-10-03-16.pdf.

Government of Canada (2017), Canada's National Housing Strategy: a place to call home, https://www.placetocallhome.ca/pdfs/Canada-National-Housing-Strategy.pdf. 
Government of Canada (2017), More choice and flexibility for families and caregivers, https://www.canada.ca/en/employment-socialdevelopment/news/2017/11/more choice and flexibilityforfamiliesandcaregiversstartingdecem .html.

Government of Canada (2016), Social Assistance Statistical Report: 2009-13, https://www.canada.ca/en/employment-social-development/services/socialassistance/reports/statistical-2009-2013.html.

Government of Canada (2016), Towards a Poverty Reduction Strategy - A backgrounder on poverty in Canada, https://www.canada.ca/en/employment-socialdevelopment/programs/poverty-reduction/backgrounder.html.

Guttmann, A., Gandhi, S., Hanvey, Li, P., Barwick, M. et al. (2017), Primary Health Care Services for Children and Youth in Canada: Access, Quality and Structure. In The Health of Canada's Children and Youth: A CICH Profile, https://cichprofile.ca/module/3/.

Lefebvre, P. and P. Merrigan (2003), "A new deal for families and children. Choices: Family Policy”, No. 9, no5:1, Institute for Research on Public Policy, Montreal, http://www.irpp.org.

MacDonald, D. and M. Friendly (2016), A Growing concern: 2016 Child care fees in Canada's big cities, Canadian Centre for Policy Alternatives..

Mc Farland, J. (2017), Tougher stress testing hits CMHC mortgage insurance volumes, The Globe and Mail, https://www.theglobeandmail.com/report-on-business/cmhc-says-47-per-cent-dropin-insured-mortgage-market-is-new-normal/article37126455/.

McDonald, D. and D. Wilson (2013), "Poverty or Prosperity: Indigenous children in Canada", Canadian Center for Policy Alternatives, https://www.policyalternatives.ca/publications/reports/poverty-or-prosperity.

Moyser, M. (2017), Women and Paid Work, Women in Canada : A gender-based statistical report, Statistics Canada.

OECD (2018), OECD Economic Surveys: Canada 2018, OECD Publishing, Paris, http://dx.doi.org/10.1787/eco_surveys-can-2018-en.

OECD (2017), Promising Practices in Supporting Success for Indigenous Students, OECD Publishing, Paris, http://dx.doi.org/10.1787/9789264279421-en.

OECD (2016), OECD Economic Surveys: Canada 2016, OECD Publications, Paris, http://dx.doi.org/10.1787/eco surveys-can-2016-en..

OECD (2015), Canada 2015 - Country chapter for OECD series Benefits and Wages, http://(www.oecd.org/els/social/workincentives.

OECD (2015), “Integrating service delivery for vulnerable families: Preventing disadvantage?", in Integrating Social Services for Vulnerable Groups: Bridging Sectors for Better Service Delivery, OECD Publishing, Paris, http://dx.doi.org/10.1787/9789264233775-5-en. 
Oecd (2017), OECD Economic Outlook, https://www.oecd-ilibrary.org/docserver/eco outlookv2017-2en.pdf?expires $=1536054000 \& \mathrm{id}=\mathrm{id} \&$ accname $=$ ocid84004878\& checksum $=6 \mathrm{AFA} 021859 \mathrm{D} 86 \mathrm{C}$ 5E951C0625A23DA85C (accessed on 04 September 2018).

Picot, G. and F. Hou (2014), Immigration Low Income and Income Inequality in Canada: What's new in the 2000s?, http://www.statcan.gc.ca/pub/11f0019m/11f0019m2014364-eng.pdf (accessed on 30 November 2017).

Picot, G. and F. Hou (2014), "Immigration, Low Income and Income Inequality in Canada: What's New in the 2000s?", Analytical Studies Branch Research Paper Series, Statistics Canada.

Russel, M., B. Harris and A. Gockel (2008), "Canadian Lone Mothers describe Parenting Needs: European Solutions Explored”, Social Work Review / Revue canadienne de service social, Vol. 25/2, pp. 169-85.

Salvi del Pero, A. et al. (2016), "Policies to promote access to good-quality affordable housing in OECD countries", OECD Social, Employment and Migration Working Papers, No. 176, OECD Publishing, Paris, http://dx.doi.org/10.1787/5jm3p5gl4djd-en.

Shikako-Thomas, L. and M. Law (2015), "Policies supporting participation in leisure activities for children and youth with disabilities in Canada: from policy to play", Disability \& Society, Vol. 30/3, pp. 381-400.

Sinha, M. (2014), Child Care in Canada, Statistics Canada.

Sinha, V. and A. Kozlowski (2013), "The Structure of Aboriginal Child Welfare in Canada", International Indigenous Policy Journal, Vol. 4/2, http://ir.lib.uwo.ca/iipj/vol4/iss2/2.

Statistics Canada (2017), 2016 Census of Population, Statistics Canada, https://www12.statcan.gc.ca/census-recensement/2016/dp-pd/dt-td/Rpeng.cfm? $\mathrm{LANG}=\mathrm{E} \& \mathrm{APATH}=3 \& \mathrm{DETAIL}=0 \& \mathrm{DIM}=0 \& \mathrm{FL}=\mathrm{A} \& \mathrm{FREE}=0 \& \mathrm{GC}=0 \& \mathrm{GID}=0 \& \mathrm{G}$ $\mathrm{K}=0 \& \mathrm{GRP}=1 \& \mathrm{PID}=111095 \& \mathrm{PRID}=10 \& \mathrm{PTYPE}=109445 \& \mathrm{~S}=0 \& \mathrm{SHOWALL}=0 \& \mathrm{SUB}=0 \& \mathrm{Te}$ mporal $=2017 \&$ THEME $=122 \& \mathrm{VID}=0 \& \mathrm{VNAMEE}=\& \mathrm{VNAMEF}=$.

Statistics Canada (2017), “Aboriginal Peoples in Canada: Key results from the 2016 Census:”, The Daily (25 October 2017).

Statistics Canada (2017), "Census in Breif: Children with and Immigrant Background: bridging cultures", 2016 Census Analytical Products, http://www12.statcan.gc.ca/censusrecensement/2016/as-sa/98-200-x/2016015/98-200-x2016015-eng.pdf (accessed on 30 November 2017).

Statistics Canada (2017), Census in Brief: Children with an Immigrant Background: bridging cultures, Statistics Canada.

Statistics Canada (2017), Core housing need, Census 2016, Statistics Canada, http://www12.statcan.gc.ca/census-recensement/2016/dp-pd/chn-biml/index-eng.cfm.

Statistics Canada (2017), Portrait of children's family life - 2016 Census in Brief, Statistics Canada. 


\section{Annex A. Background information on the policy context in Canada}

73. This annex provides information on the Canadian institutional context. Financial assistance for families, assistance with social assistance, assistance in reconciling work and family life are reviewed. Housing price trends and policies are also discussed.

\section{Financial support for families with children}

74. Income support schemes have been subject to several reforms over the past thirty years to strengthen family income, as well as to simplify the system and make it more transparent for welfare benefit recipients (Box A 1). Child benefit payments have a strong role in preventing poverty, but a key feature of the Canadian system is that child benefits are also paid to middle-income families in so far as they are aimed not only at fighting poverty but also at covering part of the costs of raising children. The recent reform introducing the Canada Child Benefit increases the level of support received by low and middle-income families. On average, families benefitting from the CCB receive about $\$ 6,800$ in CCB payments annually. About 65 per cent of families receiving the maximum CCB amounts are single parents, of whom 90 per cent are single mothers. It is estimated that the CCB will help lift about 300,000 children out of poverty. 


\section{Box A 1. Child benefit schemes in Canada}

Providing families with adequate income to raise children is one key element of government action at federal of provincial levels. Child benefit system has been reformed several times over the past decades, but a striking feature of reforms in this area lies also in the step-by-step integration of the different benefits received by families since the early 1990s. For instance, in 1993 the federal government reformed the family benefits package by replacing three programs that differed in purpose, design and distributional impact (Family allowances, a refundable Child Tax Credit that was very progressive and geared to poor families, and a non-refundable Child Tax Credit from which most poor families were excluded) ${ }^{3}$ with the Child Tax Benefit (Battle, 2015 [19]).

The National Child Benefit ${ }^{4}$ was introduced in 1998 as an intergovernmental initiative aimed at preventing and reducing child poverty. This program, as well as the Child Tax Benefit, offered several advantages in comparison to the older system. As a nonstigmatizing program, it delivered its benefits to the large majority of Canadian families through the same vehicle, and was portable in the sense that it provides a stable and assured supplement to income no matter where families lived or moved. It was progressive, meaning benefits decreased as incomes rose and it was not taxable, so that the amount received by a family was directly transparent.

Several other measures were also introduced to help parents offset the cost of whatever childcare arrangement they choose. In July 2006, the federal government introduced the Universal Child Care Benefit, a direct payment to all Canadian families regardless of income for each child under the age of six and a reduced rate for children 6-17 years old. In addition, the federal personal income tax system provides a childcare expenses deduction for families with children.

A further step towards benefit integration was taken with the introduction in 2016 of the Canada Child Benefit, which replace the previous Child Tax Benefit, the National Child Benefit Supplement and the Universal Child Care Benefit to provide all in one benefit for all families with children under age 18 . For low-income families with less than CAD 30,000 in annual net income, the CCB provides a maximum annual benefit of CAD 6400 per child under the age of 6 and up to CAD 5400 per child aged 6 to 17 - and an additional CAD 2,730 per child eligible for the disability tax credit - from which it is expected that around 300,000 children will be lifted out of poverty compared to before the reform. The reform also places greater weight on the parental recognition objective for non-poor households, and for these reason child payments for middle- and most high-income families are also boosted. Families with higher incomes consequently receive progressively less than low-income families, until the CCB phases out entirely for the richest families. The structure of the benefit is progressive and consequently almost "universal" in the sense that while first designed to combat poverty, it also aims to support middle-class families.

In fall 2017, the government has proposed to strengthen the CCB by increasing the benefits annually to keep pace with the rising cost of living as of July 2018. Indexing the CCB for the 2018-19 benefit year will provide an additional \$5.6 billion in support to Canadian families over the 2018-19 to 2022-23 period. As an example of the benefit of this proposed change, for the 2019-20 benefit year, for a single parent with $\$ 35,000$ of income and two children (one under the age of 6 and one aged 6 to 17), the accelerated indexation of the CCB will contribute $\$ 560$ more towards the increasing costs of raising his or her children (Department of Finance, 2017[20]). 


\section{Social assistance geared towards returning to employment}

75. Important changes in the area of social assistance policies have been introduced over the past decade mainly to facilitate or enable returns to work of social assistance recipients. To this aim, most provinces have introduced training activities for social assistance recipients in an effort to improve their skills and employment potential. Several provinces and territories also offer ancillary supports, such as child care, community start-up, and transportation allowances, in combination with employment assistance, in order to facilitate social assistance recipients' participation in the labour market (Government of Canada, 2016 [21]) (OECD, 2015[22]).

76. Moreover, in an effort to further lessen the financial impact of the transition from social assistance to employment, several provinces and territories have extended coverage of supplementary health benefits including prescription drugs for a specified period of time after exiting social assistance. Some jurisdictions have also introduced earned income supplements. The purpose of these supplements is to increase the financial benefit associated with employment for persons with low wages. Similarly, recent reforms to asset and earnings exemption levels in some jurisdictions have allowed social assistance recipients to accumulate certain types of assets.

77. Pointing to the same direction, the federal tax system was reformed with the introduction in 2007 of Working Income Tax Benefit, providing a refundable tax credit to lower the welfare wall and to make work pay for low- and modest-income families.

78. For 2019 and subsequent taxation years, the government has proposed to introduce the Canada Workers Benefit (CWB), an enhanced version of the Working Income Tax Benefit (WITB). Compared to the WITB, the CWB will increase both the maximum benefits received, as well as the income level at which the benefit is phased out completely. As a result, a low-income worker earning $\$ 15,000$ would receive up to almost $\$ 500$ more from the CWB in 2019 than in 2018. The new scheme is expected to encourage more people to join the workforce and to raising roughly 70,000 Canadians out of poverty, while also benefiting households in the middle class. This reform implies an increase in expenditure: in 2017 the federal government spent $0.05 \%$ of GDP on the WITB, and spending on the CWB will increase to around $0.09 \%$ of GDP in 2019 .

79. These reforms are particularly useful in reaching people furthest from the labour market for social, health or health reasons or because of their lack of readiness to return to work. However, low-income families do not always have a financial interest in both parents or a lone parent participating in the labour market. The excessive level of effective taxation of income generated by a shift from social assistance to employment may indeed be an obstacle to employment. Canada's effective tax rates when parents move from social assistance to low paid employment that are far above the OECD average for couple families with two children, but much lower than the average for single parents (Figure A 1).

\footnotetext{
${ }^{3}$ In addition, the Child Disability Benefit granted to help low and middle-income families with a severely disabled child.

${ }^{4}$ The National Child Benefit (NCB) was a joint initiative of Canada's federal, provincial and territorial governments, which included a First Nations component. The National Child Benefit aimed to prevent and reduce the depth of child poverty in Canada, promote labour market attachment by ensuring that families will always be better off as a result of working, and reduce overlap and duplication by harmonizing program objectives and benefits across jurisdictions. The NCB Supplement (to the CCTB) was the federal government's contribution to the NCB initiative.
} 
Figure A 1. Average Effective Tax Rates for a transition into full-time work, 2015

For persons without entitlement to unemployment insurance but entitled to social assistance

Panel A: Couple family with two children
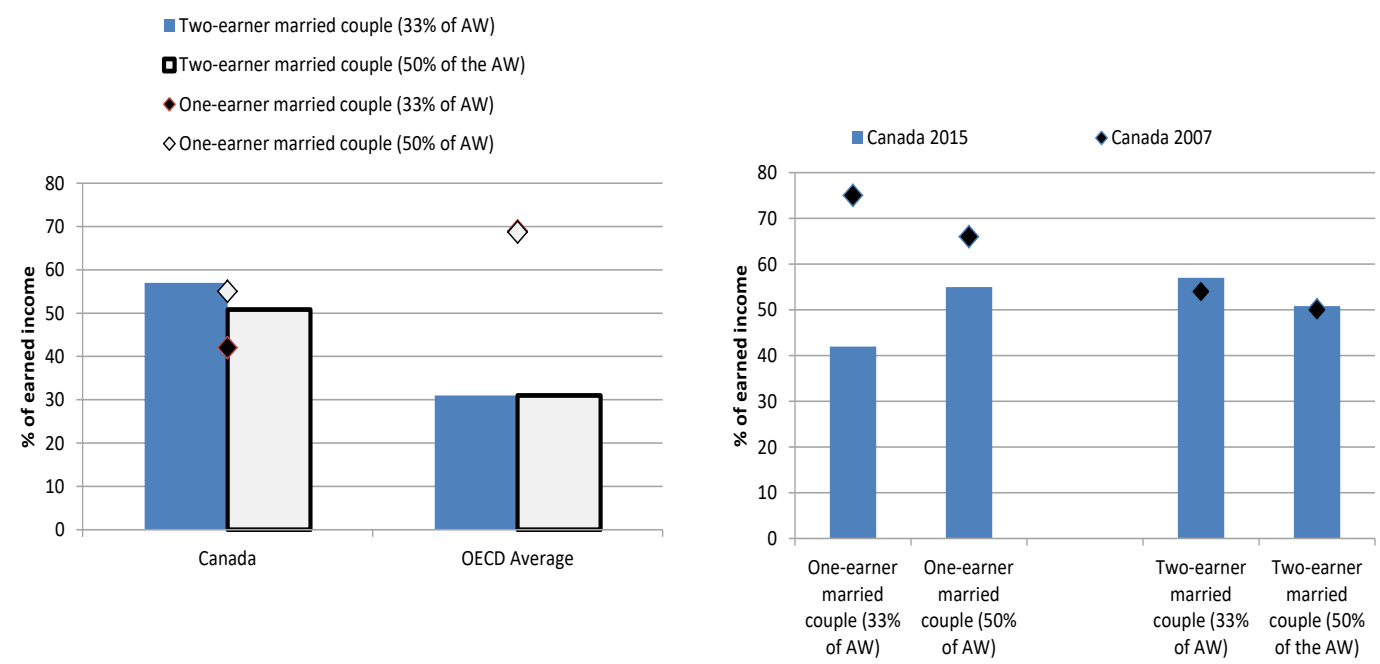

Panel B: Single parent family with two children
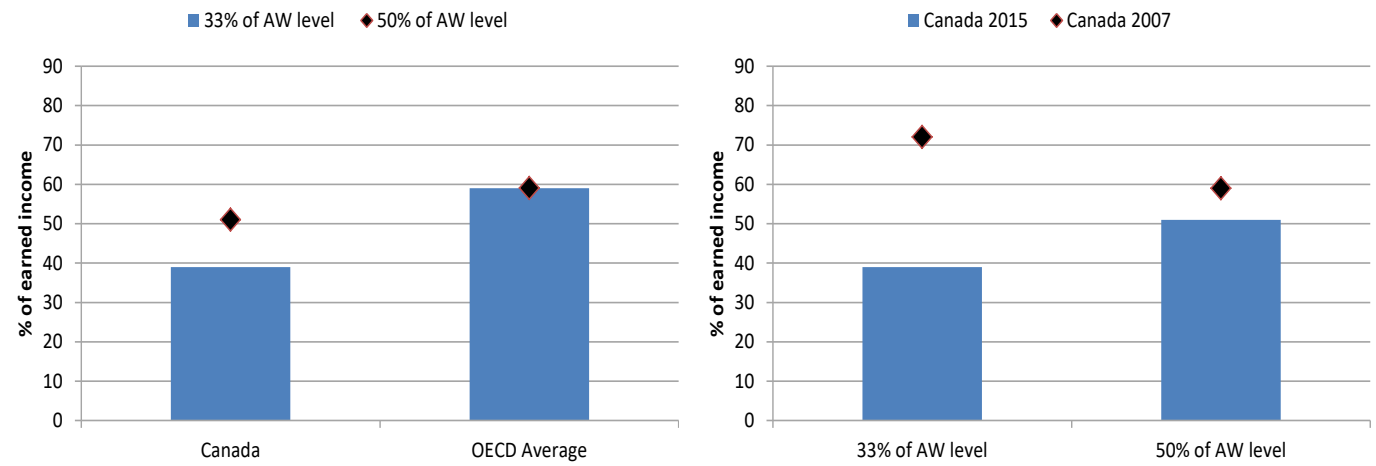

Note: The effective tax rate for individuals is the average rate at which their earned income is taxed. The estimates here relate to the situation of a person who is not entitled to unemployment benefits (e.g. because entitlements have expired). Instead, social assistance and other means-tested benefits are assumed to be available subject to relevant income conditions. Where receipt of such assistance is subject to activity tests (such as active job-search or being "available" for work), these requirements are assumed to be met in the out of work situation. Cash housing benefits are calculated assuming private market rent, plus other charges, amounting to $20 \%$ of the full-time wage for all family types. The percentage of AW relates to the earnings from full-time employment of the individual moving into work. For married couples, the percentage of AW relates to one spouse only; the second spouse is assumed to be inactive with no earnings in a one-earner couple and to have full-time earnings equal to $67 \%$ of AW in a two-earner couple. Calculations for families with children assume two children aged 4 and 6 .

Source: OECD Tax \& Benefit model, http://www.oecd.org/els/soc/benefits-and-wages.htm. 


\section{Support to facilitate work-life balance}

80. Ensuring that parents, especially women, are able to reconcile work and family life is one of the measures that will help to reduce family and child poverty. Two types of measures go in this direction: leave from work for parents when a child is born; and childcare services before and after school age.

\section{Leave policies}

81. In Canada, working parents are granted a right to employment-protected leave around the time of childbirth or adoption, and (in provinces and territories other than Quebec) the federal government is responsible for legislating and providing financial benefits to support parents in taking leave at this time. In Canada outside of Quebec, Employment Insurance provides up to 15 weeks of maternity benefits for mothers and up to an additional 35 weeks or 61 weeks (explained below) of parental benefits for either parent (or split between them) since the extension of rights that was introduced in 2009. To qualify, parents have to have accumulated 600 or more hours of paid employment, and for this reason, many young mothers without permanent work are ineligible. Self-employed persons are eligible for benefits only if they opt into the program and pay premiums for at least one year prior to claiming benefits.

82. Eligible parents receive $55 \%$ of their previous weekly earnings up to about $\$ 50,000$ (adjusted annually) which provides a maximum weekly payment of about $\$ 525$ per week, and a small proportion of low-income mothers is eligible for $80 \%$ of their previous weekly earnings. In this situation, the period around childbirth can be associated with a drop of household earnings and increased risk of having disposable income falling below the poverty line, as it is particularly the case for single earner families with low to average earnings (Figure A 2).

83. Most recently, the Canadian government announced new Employment Insurance Special Benefits provisions to provide caregivers with more choice (Government of Canada, $2017_{[23]}$ ). Since 3 December 2017, caregivers have access to a benefit of up to 15 weeks, and parents will be able to choose between 35 and 61 weeks of parental leave. The maximum weekly benefit is $\$ 543$ per week or $\$ 326$ per week for those taking 61 weeks of parental leave. Hours required to qualify for benefits remains at $600 \mathrm{~h}$ in the past 12 months. Mothers will also be able to start maternity benefits up to 12 weeks before the birth of their child but the total weeks of maternity leave is still 15 weeks.

84. Parental leave insurance benefit can be received by parents returning to work, up to a certain limit. Until August 11, 2018, a "Working While on Claim" pilot project is in place which changes the way the weekly EI parental benefits is treated for parents returning to (part-time) work. Under this pilot project, once the parent has served the waiting period, he/she is able to keep 50 percents of the EI benefits for every dollar earned, up to $90 \%$ of the weekly insurable earnings that is used to calculate the EI benefit amount. Any money earned above this threshold is then deducted dollar for dollar from the parental benefit. An additional five weeks (or eight weeks at a lower pay rate) of non-transferable leave for second parents (usually fathers, but also available to adoptive and same-sex couples) has also been introduced by the federal government in 2018 . 
85. This reform therefore introduces a certain flexibility regarding when a mother can start maternity leave, and by proposing new options for parental leave. In the face of uncertainty about the availability of affordable child care, some parents may prefer the option of a longer and lower paid leave to guard against the risk of not finding a child care option in a sufficiently short period of time. However, the reduced level of income support and the prolonged period out of work may weaken labour force attachment, and can exacerbate the risk of poverty that already weighs on low-income families, especially single-parent families (Figure A 2).

86. In addition, the decision to take a parental leave and its duration must be taken at the beginning of the period, which implies that parents must anticipate with as much certainty as possible the type of care they will have at the end of the leave. In order to make the most informed decision possible, it is necessary for parents to have the most complete information possible on the childcare pathway before even taking a leave of absence.

87. Greater responsiveness could be achieved by allowing more flexible use of leave entitlements. For instance, some parents may have access to part-time childcare, for which a part-time leave could be a better solution for their constraints.

Figure A 2. Equivalised income across child life-cycle, 2014

Equivalised disposable household income as a proportion of the median equivalised disposable household income, by family type. Single parent - two children - 50\% AW
--- Single parent - two children - $100 \%$ AW
- - - - Single-earner couple - two children - 50\% AW + 0\% AW Median disposable income

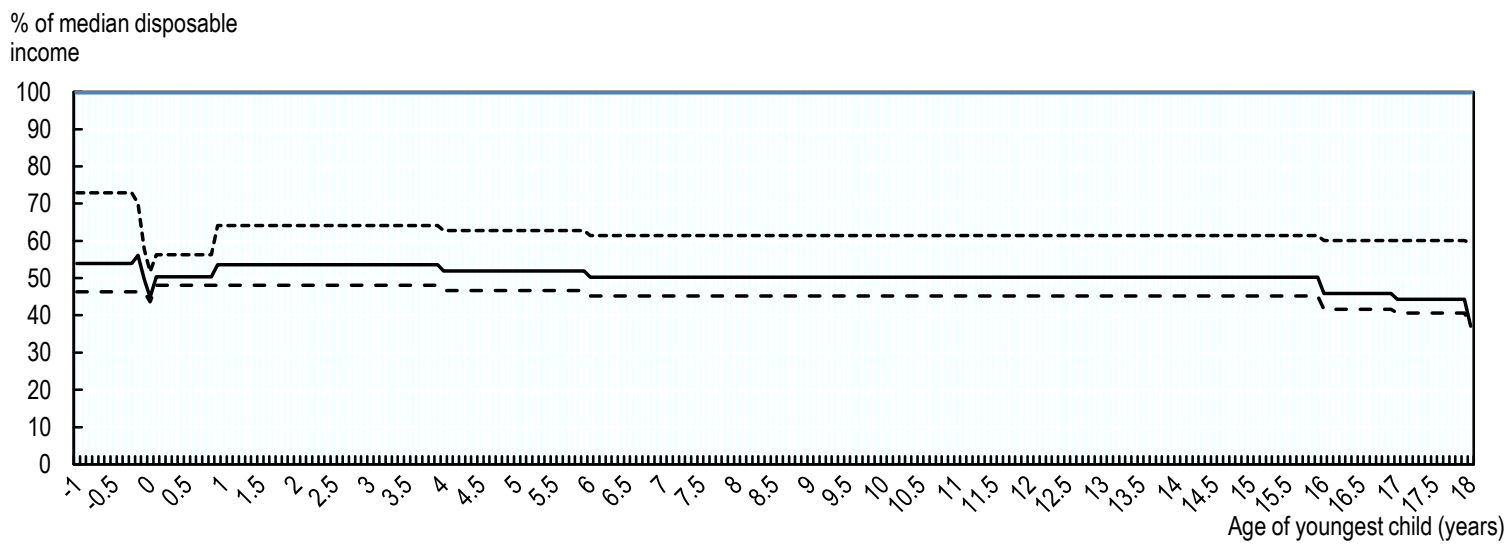

Note: Calculations take into account the taxes and social security contributions due on earnings and benefits. Birth-related leave payments, social assistance benefits, family benefits, housing benefits and in-work benefits are also included in the calculations. Parents are assumed to take all available maternity and paternity leave (including unpaid maternity and paternity leave) in one spell and at the earliest possible opportunity, regardless of the payment level. This may result in mothers starting maternity leave during late pregnancy (before birth). The figure reflects rules applying in 2014 and therefore foes not reflect the 2017 child benefit reform.

Source: OECD Family Support Calculator based on Tax \& Benefit models, http://www.oecd.org/fr/els/soc/oecdfamilydatabasethefamilysupportcalculator.htm. 
88. Since 2013, parents needing to be absent from work to provide care or support to a critically ill or injured child can also claim for EI special benefits for Parents of Critically Ill Children (PCIC) for up to a maximum of 35 weeks, which is below the 37,5 weeks granted on average across the OECD.

\section{Childcare policies}

89. Childcare is an important area of State intervention in Canada, for which Federal, Provincial and Territorial authorities share responsibilities. At federal level and in some provinces, a greater emphasis has been put on the expansion of childcare services since the mid-1990s to accompany the rapid increase in mothers' labour force participation as well as to enhance the development of disadvantaged children and tackle poverty (Lefebvre and Merrigan, 2003 $\left.{ }_{[9]}\right)$.

90. Childcare policies vary greatly across provinces that have different ways to lead the development of early childhood services (Box A 2). Services for children are provided through full-day ECEC centres (including kindergartens), part-day preschools, home/family childcare, school-age and family resources programs of which the mix varies across provinces and is determined at the local level based on a planning process taking into account community needs and priorities. Services that seamlessly provide "care" and "learning" for children are also offered across Canada, with parenting support resources integrated into service provision.

91. Because the fragmented nature of childcare policies, there are no recent statistics available on the investment effort made in Canada to develop childcare and education services at country level. There is evidence, however, that the budget devoted to the development of this sector varies greatly across Provinces and Territories from $1.1 \%$ of provincial budget for instance in Northwest Territories to 4.3\% in Québec (Abkari and MacCuaig, 2018[24]).

92. Service coverage also varies across provinces (Sinha, 2014 $4_{[25]}$ ). In 2012, nearly half (46\%) of the children (1-5 years of age) of mothers who were employed or were full-time students used regulated care, and only $12 \%$ used paid care by a non-relative (informal care) (Cleveland, 2015[26]). Childcare was more often used for children aged 1 to 4 (54\% of parents use formal care) than for children above age $4(39 \%)$. Cross-regional variations are also large: rates of childcare were highest in Quebec (58\%) and lowest in Manitoba (34\%), Alberta $(40 \%)$ and Ontario (43\%). Moreover, $60 \%$ of parents used their main childcare arrangement on a full-time basis, meaning at least 30 hours a week.

93. The fragmentation of the information system also makes it impossible to describe precisely the differences in access to childcare according to families' standard of living or other social characteristics. Nevertheless, the available evidence suggests that the participation in preschools is low in international comparison. Only $56.7 \%$ of 3-to-5 yearolds participate, compared with the OECD average of $84 \%$.

94. The net cost of childcare is among the highest in the OECD (Figure 12). Efforts to increase the supply and improve the affordability of childcare are a longstanding policy priority, but have had mixed results since regulated services are often unaffordable (MacDonald and Friendly, 2016); long wait lists and hefty surcharges keep many children out (MacDonald and Friendly, 2016), and the gender employment gap is higher in provinces with the highest cost of median child care (Moyser, 2017 $7_{[12]}$ ). 


\section{Box A 2. Childcare policies in Canada}

In Canada, education and childcare policies fall primarily within the jurisdiction of provinces. Some jurisdictions have opted to expand access to early childhood programs through their education systems (Akbari and McCuaig, 2014 ${ }_{[27]}$ ) (Abkari and MacCuaig, 2018 $8_{[24]}$ ). Seven out of the 13 provinces and territories now offer full-day kindergarten for 5 -year-olds. Ontario and the Northwest Territories are extending full-day programming for 4-year-olds, and Saskatchewan, Manitoba and Alberta have expanded access to 3- and 4-yearsolds in at-risk circumstances. Education departments have also become more proactive in preparing preschoolers for kindergarten.

Education departments have increased their involvement in the development of programs for young children, but in provinces other than Quebec they are often reluctant to operate programs beyond regularly scheduled school hours. Regional school boards have responded to the needs of working parents by providing extended hour programming. In addition to Quebec, some school boards in the Northwest Territories, Alberta and Ontario provide beforeand after-school programs. In Ontario, where four school boards have opted to directly provide out-of-school care, access has quadrupled, fees have decreased and early childhood educators are enjoying the benefits of public sector employment (Akbari and McCuaig, $\left.2014_{[27]}\right)$. Quebec and Prince Edward Island managed the introduction of full-day kindergarten with a comprehensive transition plan that refocused childcare operators to provide services for younger aged children.

There is also a long history of federal involvement both through transfers to individuals and to provincial and territorial governments. For instance, as the federal increased payment under the NCB supplement, the provinces and territories agreed to 'reinvest' the amount saved in other programs and services for low-income families with children, such as early learning and child care services, supplementary health care, income-tested child benefits and earnings supplements. As a consequence, the Early Childhood Development Initiative (ECDI) adopted in 2000 and was accompanied with CAD 500 million annually for programs to promote infant and maternal health, improve parenting and community supports and strengthen early learning and child care. The agreement was significant as it took a holistic view of early childhood as a process that begins in utero and continues to formal schooling. Most provinces focused their efforts on information and parenting resources, while scant amounts were targeted to early learning and care programs.

Building on this first commitment, the 2003 Multilateral Framework Agreement on Early Learning and Child Care (MFA) provided \$250 million annually exclusively for programs for preschool-aged children. Provinces and territories were to meet broad principles in their spending and agreed to enhance accessibility, quality, inclusion and parental choice. Unlike past agreements for child care, funding was not targeted to low-income families, and the concept of accountability was introduced. Both the ECDI and MFA had specific requirements for each jurisdiction to issue annual reports on their progress. After these first initiatives, federal investments in childcare area have been sustained but with back and forth ${ }^{5}$.

Most recently (in June 2017), the Federal, Provincial and Territorial governments adopted to renewed "Multilateral Early Learning and Child Care Framework" setting a foundation for governments to work toward a shared long term vision where "all children can experience the enriching environment of quality early learning and child care that supports children's development to reach their full potential". This Framework sets the foundation for collaboration and additional federal investments in provincial and territorial early learning and childcare systems. Governments recognize that each jurisdiction has the responsibility to develop systems that best respond to the needs and priorities of their communities. The implementation of this framework is supported by federal government investments announced in Budgets 2016 and 2017 totalling \$7.5 billion over 11 years to support and create more highquality, affordable child care across the country. 


\section{Housing prices and policies}

95. Canadian house prices have more than doubled in real terms since 2000, outpacing incomes and rents $\left(\mathrm{OECD}, 2018_{[8]}\right)$. House prices have increased more strongly than rents, so that house prices relative to rents have risen sharply (Figure A 3). Increases in house prices slowed down around the period of the financial crisis, but then price inflation went back to its pre-crisis level. Overall, house prices in household income increased sharply, and after falling around 2008, the house price to rent ratio returned to rising sharply. Recently, house prices declined in energy-producing regions, continued to rise strongly in Vancouver and Toronto, and have risen modestly elsewhere. In this context, the purchase of real estate often becomes unaffordable for low-income families who, as it will be seen in the next section, are increasingly likely to rent their homes.

Figure A 3. House prices are historically high relative to rents

Evolution of house prices and rents, Indexes 2010=100
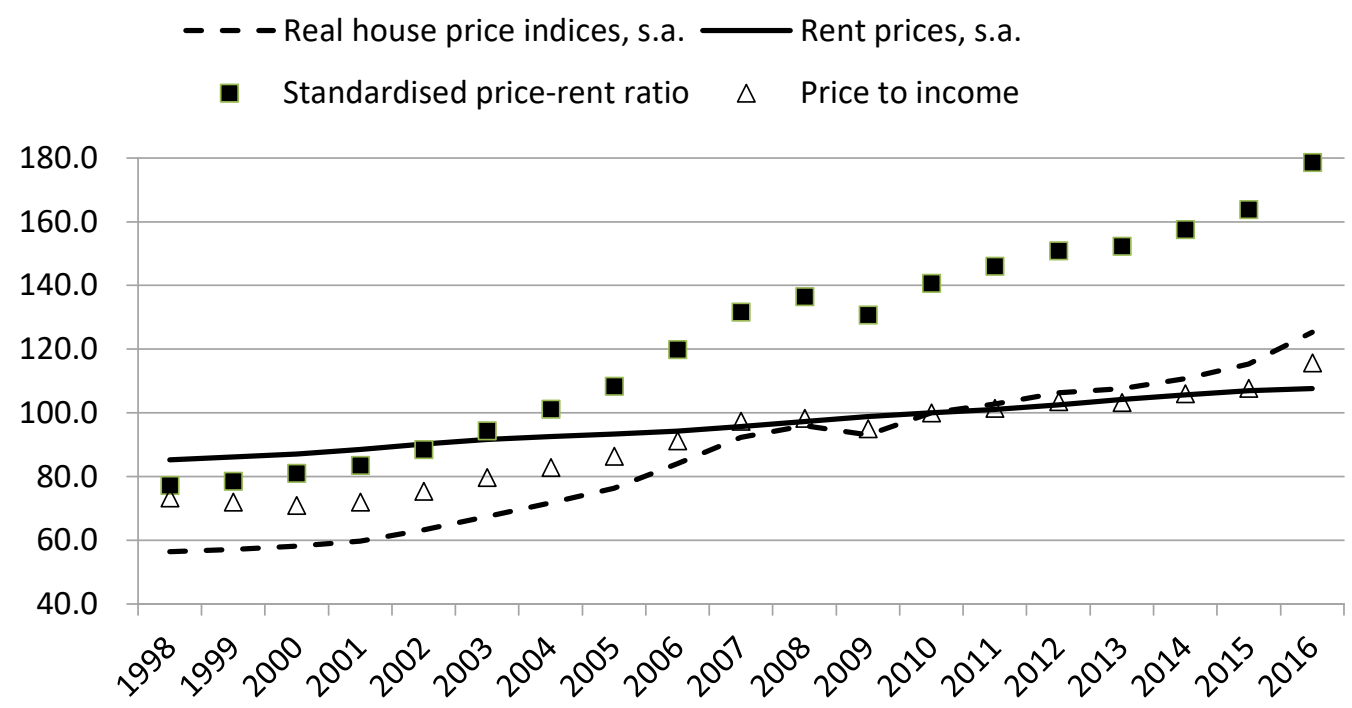

Note: Nominal house prices deflated using the private consumption deflator from the national account statistics. The standardised price-rent and price-income ratios show the current price-rent and price-income ratios relative to their respective long-term averages. The long-term average, which is used as a reference value. Price to income ratio ris calculated as nominal house prices divided by nominal disposable income per head.

Source: OECD House Price Indicators.

\footnotetext{
${ }^{5}$ For instance, a national initiative was announced in 2005 to support the development of early learning and childcare across the country. As a condition of \$5-billion in funding over 5 years announced with this initiative, provinces signed bi-lateral agreements-in-principle committing to develop detailed action plans that identified their spending priorities for early learning and childcare. However, in March 2007, the \$5-billion commitment disappeared. Instead, \$250 million a year was earmarked for a Community Child Care Investment Program and transferred to provincial and territorial governments. A 25 percent tax credit was made available to businesses to create licensed child care spaces in the workplace. Following this, a Child Care Spaces Initiative (CCSI) was developed in 2007 to provide an incentive to employers to create workplace childcare. However, by bypassing provincial/territorial governments, it undermined their newly-found role in early childhood service development and the initiative has been discontinued.
} 
96. Persistently low mortgage interest rates have offset the associated pressures on the affordability of housing (Box A 3), and partly for this reason the median housing cost born by home owners $(17 \%)$ is lower than those born by households renting their dwelling $(25 \%)$ (Figure A 4, Panel A). However, housing cost burden is considerably higher for the poorest households: half of tenants in the bottom quintile of the income distribution spend more than $38 \%$ of their disposable income on housing; housing cost burden is higher for low-income owners, with half of them spending more than $42 \%$ of their disposable income on housing. Also, slightly more than $43 \%$ of low-income tenants spend more than $40 \%$ of disposable income on housing, and the proportion creeps up to $48 \%$ for home owners. 
Figure A 4. Housing cost burden is considerably higher for the poorest households, 2011

Panel A: Median mortgage burden (principal repayment and interest payments) or rent burden (private market and subsidized rent) as a share of disposable income, in percent of disposable income.

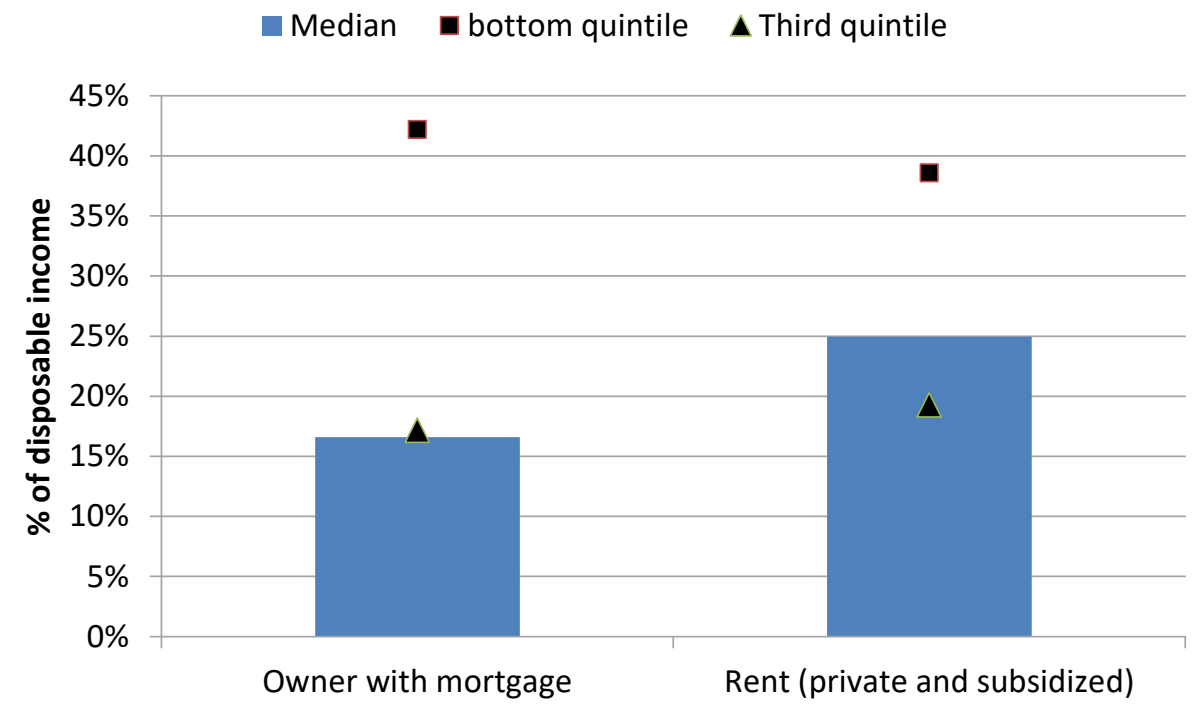

Panel B: Proportion of population in the bottom quintile of the income distribution spending more than $40 \%$ of disposable income on mortgage and rent

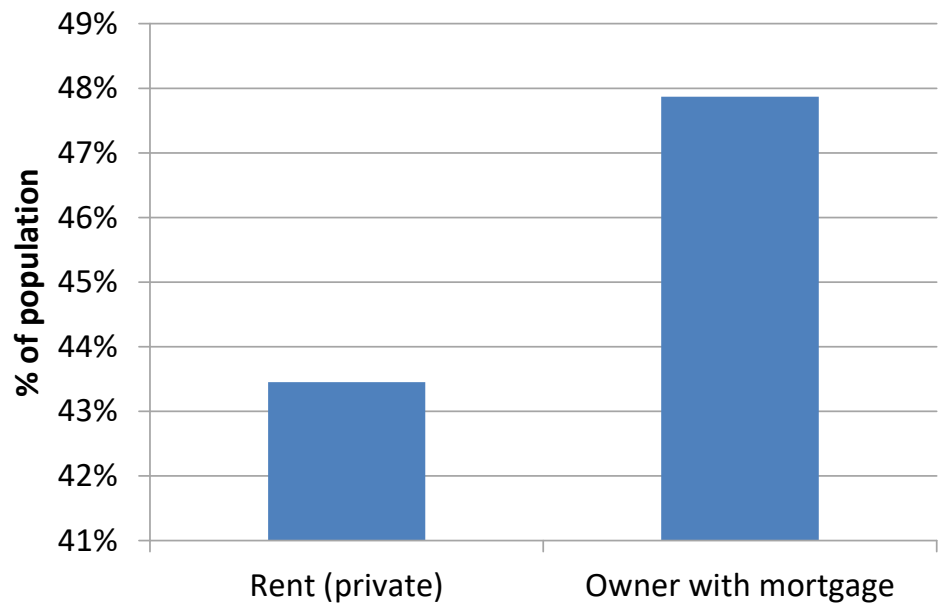

Note: OECD calculations based on the Survey of Labour and Income Dynamics (SLID) 2011. The median cost is calculated for each quintile.

Source: OECD Affordable Housing Database. 


\section{Box A 3. Housing Policies in Canada}

In 2016, an OECD questionnaire on Social and Affordable Housing was sent to countries to identify key objectives of housing policies, challenges and key features housing programs. Canadian authorities identified the following four key objective: (1) help Canadians in need access affordable (set as the most important); (2) help Aboriginal Canadians to improve their living conditions with sound and suitable housing; (3) provide mortgage loan insurance products and tools to Canadians and contribute to the stability of the housing; and (4) ensure an adequate supply of funds for mortgage lending through mortgage securitization while considering the competitiveness, efficient functioning and stability of the housing finance system market (Salvi del Pero et al., 2016 $[28]$ ).

The main obstacles and challenges reported in the same questionnaire were: the growing house prices, particularly in urban areas; the limited supply of affordable rental housing; the difficulties in meeting on-reserve housing needs; and the absence of a well-functioning housing market in many small northern communities. In 2016 , slightly less than $13 \%$ of households are in "core housing need", i.e. living in a dwelling that is considered unsuitable, inadequate or unaffordable and whose income levels are such that they could not afford alternative suitable and adequate housing in their community (Statistics Canada,

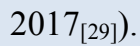

A series of macro-prudential measures adopted since 2008 have sought to lower housingmarket risks, including tightening loan-to-value caps, with a debt-servicing "stress test" against a standardised rate. In November 2017, the Federal Government launched the development of a National Housing Strategy (NHS) (Government of Canada, 2017[30]) in view of improving housing in Canada and will focus on addressing the needs of the most vulnerable populations living in inadequate housing. The National Housing Strategy will make a number of significant investments in new homes built, renovations of existing housing stock through a CAD 15.9 billion National Housing Co-Investment fund (CAD 4.7 billion in contributions and the remainder in low-interest loans) and improving housing affordability by providing federal lands to community and affordable housing providers and CAD 4.3 billion in support to provinces and territories (who administer $80 \%$ of community housing in Canada) to maintain and build new units of community housing through the Canada Community Housing Initiative (ibid). A housing benefit is also envisaged to be launched in 2020 (ibid). The implementation of the strategy, which will involve an expected federal investment of CAD 40 Billion over 10 years, will be led by the Canada Mortgage and Housing Corporation (CMHC). A crown-corporation, CMHC's provides mortgage loan insurance products and leads federal affordable housing investments which together contribute to the stability of the housing market and the financial system in Canada. The implementation of a new mortgage rate stress test (Canada Mortgage and Housing Corporation, 2017 [31] $)$ may make it harder for some low-income home buyers to purchase a home $\left(\mathrm{OECD}, 2018_{[8]}\right)$. Close coordination between federal and provincial authorities is critical, however: provincially regulated financial institutions should be encouraged to adhere to federal mortgage underwriting standards and monitoring of systemic risks I relations with securities markets and pricially regulated institutions is needed (OECD, 2018 $\left.{ }_{[8]}\right)$

As in many other OECD countries, home owners in Canada enjoy subsidies through a favourable tax relief to support access to home ownership: the Home Buyers' Plan (HBP) assists first time home buyers with saving accounts by allowing them to withdraw up to CAD25, 000 from a Registered Retirement Savings Plan (RRSP) to purchase or build a home. Amounts withdrawn as part of the Home Buyers Plan must be repaid within a 15year period. In addition, the First-Time Home Buyers' Tax Credit is a non-refundable federal tax credit, which provides up to CAD 750 granted as a one-off payment to first- 
time home buyers. Home-owners can also benefit from a tax rebate (the GST/HST New Housing rebate) which is offered for existing homes to cover renovation costs.

Low-income tenants also receive financial assistance at regional level but rent supplement and housing allowance programmes vary across Provinces and Territories.

Social housing programmes also provide subsidized housing that is usually targeted to lowto moderate-income households who would otherwise be unable to afford suitable and adequate housing. It is typically owned by governments, non-profit groups or cooperatives. However, social housing has not expanded significantly since the early 1990s, and much of the stock is ageing and needs repair and and maintenance. Social rental dwellings represents less than $5 \%$ of housing stock in Canada while it is for instance more than one third in the Netherlands (OECD, 2018 $[8])$.

\section{Children and family services}

97. The provision of recreational, sports and social infrastructure is important for children to be able to thrive and develop physically and socially. However, this offer is very uneven depending on the environment in which children live. Responsibilities in this area are shared between the federal and provincial governments, with other players also involved in the field. For instance, recreation and social services are in the jurisdiction of provinces, but the federal government provides guidelines, recommendations, funding allocations, and programs that relate to leisure. The federal government also establishes formal mechanisms for cooperation between the federal and provincial jurisdiction in matters relating to sport, fitness, and recreation.

98. The lack of integration across jurisdictions, and the lack of clarity about which departments are responsible for the intersection of children, disabilities, and leisure are factors restraining access to leisure activities by disable children (Shikako-Thomas and Law, $2015_{[32]}$. While all provinces have specific disability-related policies, very few have leisurespecific items within their disability policies or, when leisure-specific policies are available, there are few specific mechanisms related to children.

99. Nutritional and pro-health behaviours are also an area of joined effort to promote best practices. For instance in 2014, Health Canada, the Canadian Paediatric Society, Dietitians of Canada and the Breastfeeding Committee for Canada published a Joint Statement for the Nutrition for healthy term infants, with recommendations for feeding older infants and young children. This statement provides health care professionals with evidence-informed advice for communicating accurate and consistent information to Canadian parents and caregivers.

100. Health Canada and the Public Health Agency of Canada also provide The Eat Well and Be Active Educational Toolkit, which is designed to help persons who teach groups of children and adults about healthy eating and physical activity, and encourage individuals to take action to maintain and improve their health. 
101. Most family services that are related to issues such as domestic violence, child protection, parenting supports, and case management are delivered by sub-national governments and through non-governmental agencies. The federal government provides a patchwork of targeted supports through grants and contributions programs for initiatives such as support for veterans' families, supports for the families of convicted federal offenders incarcerated in federal prisons, and supports for new immigrants and refugee families. Family services for Indigenous Canadians is complex as the federal government provides funding to provinces, territories and Indigenous child welfare agencies for the implementation of programs including family services for Indigenous people living on reserve; provincial and territorial governments are responsible for funding for all other people including Indigenous people living off reserve (Sinha and Kozlowski, 2013 ${ }_{[33]}$ ). 


\section{Annex B. Changes in children's living standards between 2007 and 2014}

102. This section presents the detailed results of the analysis of changes in children's living standards between 2007 and 2014. This analysis is based on a decomposition of the factors that contributed to this evolution, the methodological details of which are included at the end of this document.

103. This decomposition makes it possible to identify the contribution of changes in household characteristics and changes in status with respect to parental employment to changes in the children's standard of living. However, part of the change in this standard of living is not explained by such changes in characteristics; part of this "unexplained" part reflects a change in the relationship between household characteristics and the place of children in the income distribution. In other words, it reflects a change in the effect of family characteristics on children's standard of living.

104. In addition, this decomposition is carried out by quantile of income on the whole income distribution, which makes it possible to examine the differences in evolution between so-called income poor (bottom 25\%) and non-poor children (those who above the median income) on the one hand, and according to the intensity of poverty on the other hand. For instance, trends for the bottom $25 \%$ of income distribution of children show how the standard of living has improved or gotten worse for children who are conventionally considered as poor in relative terms with a poverty line set at $50 \%$ of the median income. This evolution can be compared to those of lower percentiles (i.e. children in severe poverty) as well as to those affecting the non-poor (i.e. those with an income above the $25^{\text {th }}$ income percentile). The results reported in the main document correspond to the evolution of the income of the $25^{\text {th }}$ percentile of children.

105. Before presenting these results, it is useful to note that children's living standard is difficult to capture for the reason that the statistics on income are provided at the household level with no information on how resources and expenses are actually shared across family members. However, the distribution of children across levels of households "equivalised" income can be used to approximate the differences in children's living standard. In this perspective, income quantiles are defined as values of household income which divides the frequency distribution into equal groups, each containing the same fraction of the total population of children. 


\section{Children in two parent families}

\section{In Figure B.1. Changes in living standard of children in two parent families - Canada (2007-} 2014)

106. Panel A, the round marker shows that children in couple families at all points of the income distribution saw a relative increase in both market and disposable income. For market income, the increase was $1-2 \%$ for children - slightly lower for the $10^{\text {th }}$ percentile than the $5 \%$ rise experienced by the "bottom" 75 th percentile of the child population. There are slight variations in the magnitude of the increase of disposable income across the income distribution: for instance, all poor children taken as a whole (i.e. the bottom $25^{\text {th }}$ percentile) experienced a $6.3 \%$ increase of disposable income, while it increased by only $3.8 \%$ for the $10 \%$ poorest children, and increased by almost twice this level $(+7.2 \%)$ for the $75^{\text {th }}$ percentile.

107. This rise in living standards is explained by a number of factors:

- The rise in educational attainment of parents is the main factor raising earned income in poor families: the share fathers and mothers in poor two parent families with tertiary education, for instance, grew from 48 to $60 \%$.

- However, a significant share of the increased income (4.6\% for poor children) is not explained by any the observed changes in household characteristics, but instead it reflects the influence of unobserved characteristics and the increased "returns" of some observed characteristics. These latter changes are shown in Figure B.1. Changes in living standard of children in two parent families - Canada (2007-2014)

- Panel B in which the most remarkable feature is the sharp increase $(+30 \%)$ in the returns to employment of fathers in poor families. To some extent, this rise may reflect the gains in labour productivity (OECD, 2016[34]), but it may also reflect partly the sharp drop in the effective tax rate faced by one-earner low paid families shown in Figure A 1.

108. By contrast, several factors are associated with a decrease in income:

- The proportion of children in two-parent families who rent their homes increased sharply from 36\% to 50\% between 2007 and 2014; and this change is associated, all other things being equal, with a relative decrease in income. This association illustrates the fact that households with lower incomes tend to rent their dwellings rather than buy them, the drop in income leading to an increase in the proportion of renters. In addition, Figure B.1. Changes in living standard of children in two parent families - Canada (2007-2014)

- Panel B suggests that the standard of living of home-owners relative to tenants has increased by $23 \%$ over the same period of time, which denotes a relative impoverishment of renters and is consistent with the rise in house prices relative to rents that has occurred since 2007 in Canada. Therefore, it appears that rising house prices are pushing more and more poor families (and among them the poorest) to rent their homes and that the propensity to buy one's home becomes more and more dependent on the level of household income. The income gap (before housing costs) between poor families who own and those who do not then becomes larger.

- Changes in parental employment (such as job loss or reduced earnings) in poor twoparent families also tends to push the standard of living down. First, the drop in the number of poor children with a working father: $26 \%$ of children in the first quartile 
of families with two parents had a father out of employment in 2014, compared to $18 \%$ in 2007 . In addition, $53 \%$ of poor children have a father employed full time full year in 2014 , compared to $66 \%$ in 2007. 


\title{
Figure B.1. Changes in living standard of children in two parent families - Canada (2007-2014)
}

\author{
Market income
}

Disposable income

Panel A: Contribution of changes in family and work characteristics

\section{$\square$ Family structure \\ $\otimes$ Lfs status - father}

$\square$ Full-time full-year - mother

\author{
$\square$ Dwelling ownership \\ $\mathbf{v L f s}$ status - mother
}

Unexplained

\author{
$\square$ Education \\ $\square$ Full-time full-year - father
}
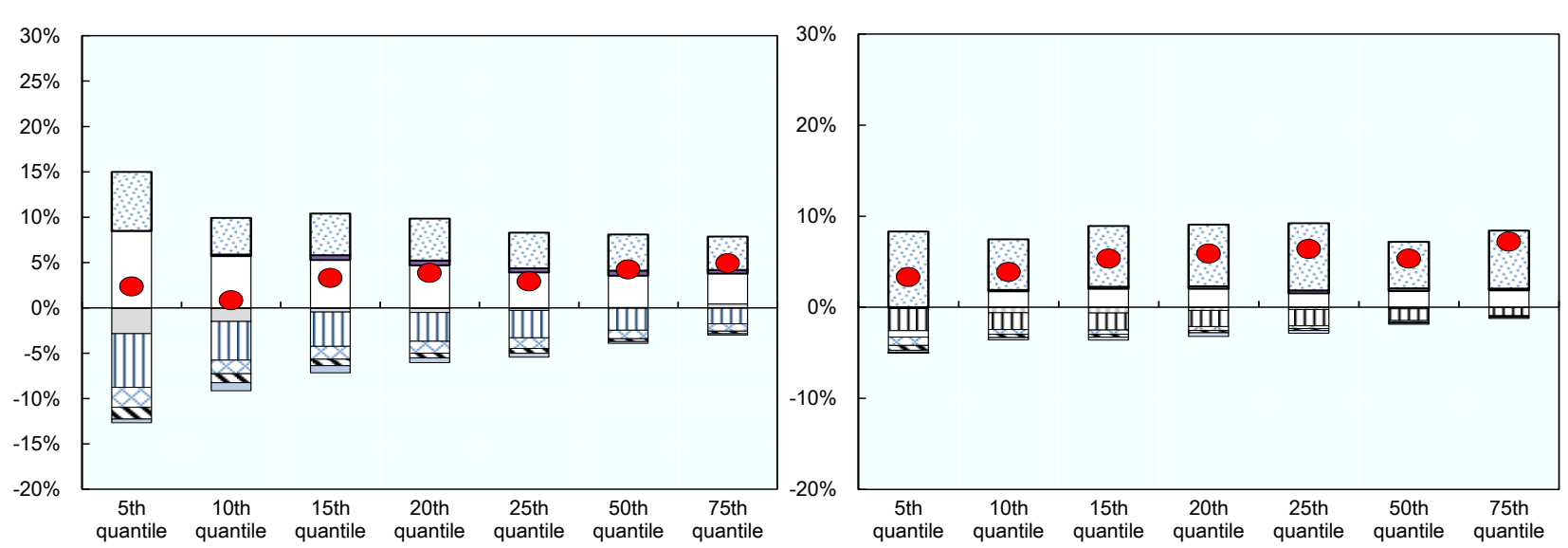

Panel B: Changes in the income returns of family characteristics
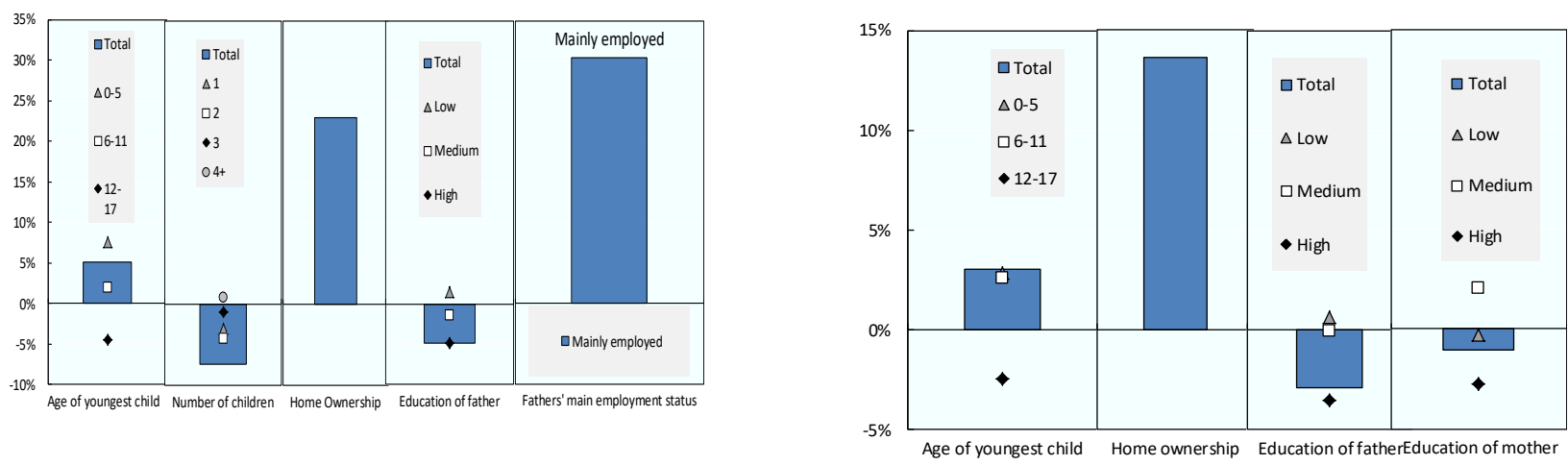

Note: Market income is the sum of: wages and salaries, net self-employment net income, interest and investment income, private pension and registered retirement savings plan income, and includes alimony or support income received, and other income; Disposable income is total income less: income tax, employment insurance contributions, public and private pension plan contributions, union dues (incl. professional membership dues, and malpractice liability insurance premiums), child care expenses incurred in order to hold a paid job, alimony or support payments paid, and public health insurance premiums. Household income is equivalised using the square root scale and adjusted for price inflation. The term 'standard of living' refers to the equivalised disposable income.

Family structure includes information on the number of children, age of children and parents, and possible presence of other adults.

The red markers in Panel A show the total percentage change in the household income quantiles from 2007 to 2014 at different point in the income distribution in two-parent families. This 'net' evolution is then decomposed in contributions of changes in family and work characteristics, plus the 'unexplained', which all can be positive if the change was associated with a relative increase in income, and negative if associated with a decrease in income, all other characteristics remaining the same.

Panel B shows how changes in the effect of each family characteristic have affected the equivalised market or disoposable income for the $25^{\text {th }}$ first percentile. A positive (negative) sign shows a gain (a loss) in income associated with the characteristic between 2007 and 2014. Only statistically significant changes are reported.

Source: OECD Estimates based on the 2007 Survey on Labour and Income Dynamics and the 2014 Canadian Income Survey. 


\title{
Children in single parent families
}

\author{
The situation of children in single parent families is different in that since 2007 they have \\ experienced a substantial loss of market income that is particularly sharp for families with \\ lowest income (Figure B.2. Changes in living standard of children in single parent families - \\ Canada (2007-2014)
}

109. Panel A). This loss is primarily due to the decrease in parental employment rates, since around $25 \%$ of children in income-poor single parent families had a parent working full-time full-year in 2014, whereas this proportion was at $40 \%$ in 2007 . This effect is strong and outweighs the upward influence on earned income due to the improvement of educational attainment of single parents (around a quarter of children lived with a parent having a low level of education in 2007, and 19\% in 2014).

110. Income poor children are also increasingly likely to live with a single parent who own the dwelling ( $+4 \%$ of poor children in single parent families), and this has been associated with a gain in market income (Figure B.2. Changes in living standard of children in single parent families - Canada (2007-2014)

111. Panel A), but it does not seem to translate into a significant increase in disposable income since there is no clear association between the evolution of disposable income and the changes in dwelling statuses.

112. The demographic profile of income poor children in single parent families is also changing: the proportion of children in single-parent families with only one child is increasing (31.6\% in $2007,36.3 \%$ in 2014$)$. Income poor children in single parent families are also getting younger: $64 \%$ of poor children in single parent families are under 12 years of age in 2014 against 59\% in 2007. In all, changes in family structure contribute slightly to the rise in income earned by single parent families $(+4 \%$ of disposable income for the bottom $75^{\text {th }}$ percentile).

113. Another striking feature is the contrast between market earnings and disposable income trends. Thus, despite a sharp drop in market income, disposable income has remained relatively stable for the $25^{\text {th }}$ first percentile, and has increased for the other single parent families. Increased social transfers to single-parent families likely explain much of the trend gap between market and disposable incomes. The effect of transfers, however, varies along the income distribution: they have barely allowed poorer (i.e., the 25th percentile) single-parent families to maintain their standard of living, while that of betteroff single-parent families has increased. The latter thus seem more likely to benefit from transfers that more than compensate for the relative loss of income from work, probably because of the higher amounts they receive from the Working Income Tax Benefit. 
Figure B.2. Changes in living standard of children in single parent families - Canada (20072014)

Market income

Disposable income

Panel A: Contribution of changes in family and work characteristics
$\square$ Family structure
$\mathbb{D}$ Dwelling ownership
$\square$ Education of parent
QLfs status of parent
$\mathbf{\Delta}$ Full-time full-year of parent
圈Unexplained

\section{- Difference}
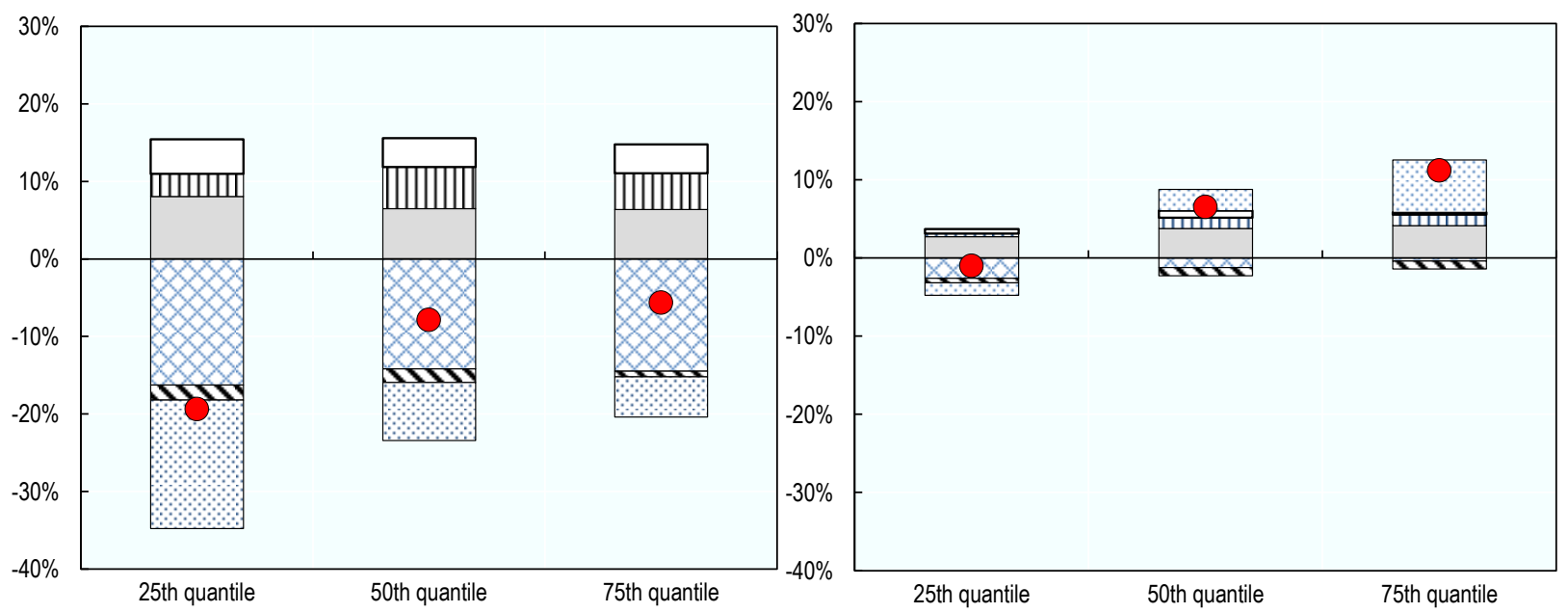

Panel B: Changes in the income returns of family characteristics
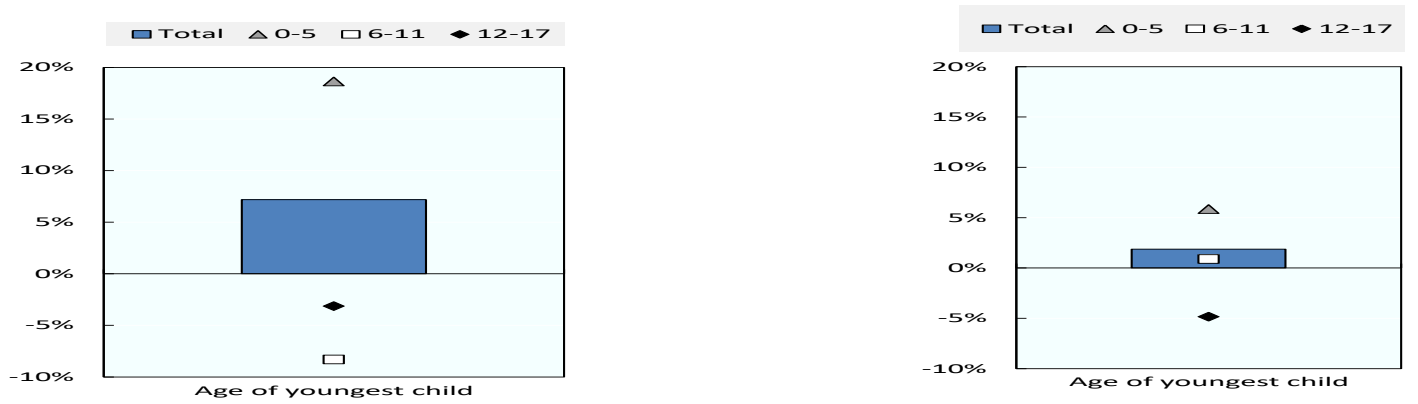

Note: The chart shows the percentage change in the household income quantile of families with children, and reflects the contribution of changes in family and work characteristics to the evolution of income. The income is equivalised and corrected for price inflation. The red markers show total changes in respectively market and disposable income for each quantile of income, and is positive (resp. negative) when the equivalised income of a given quantile has increased (resp. decreased). This total change is then decomposed in different components showing how variations in family and work characteristics have influenced the evolution of income percentiles. Panel B decomposes the "unexplained" part of Panel A in different components reflecting the changes in income "returns" of each characteristic for the $25^{\text {th }}$ percentile. Only statistically significant changes are reported.

Source: OECD Estimates based on the 2007 Survey on Labour and Income Dynamics and the 2014 Canadian Income Survey. 


\section{Methodology for the decomposition analysis of changes in children's income}

114. The empirical analysis looks at factors explaining changes in children's family income within country across time from the mid-2000s to 2014. It involves an analytical decomposition of the "contribution" of key socio-economic characteristics: such as family structures and housing status, parental labour market situations relative to changes in child poverty rates. It also looks at changes in families' income that are not explained by changes in family and work characteristics but may be due to changes in the association between these characteristics and the place of children in the income distribution. These latter changes may reflect the evolution of the institutional contexts where children live and grow up. In simple terms, the decomposition helps to measure the portion of changes in child poverty due to changes in the characteristics of child population and those due to changes in the association between these characteristics and poverty rates.

115. The decomposition is carried out for market incomes before taxes and transfers (they correspond to labour income in their vast majority, capital income being generally low for poor households), and for disposable income after social transfers. By comparing the changes in income before and after taxes and transfers, one can infer what role transfers have played in responding to changes in labour income and how this role has varied across the income distribution. It should be noted, however, that the market and disposable income distributions are considered separately, so that children in the 25th percentile of the market income distribution are not exactly the same as those in the 25 th percentile based on disposable income. The decomposition is carried out for different quantiles of the income distribution, so that the factors influencing child poverty can be compared across the income distribution.

116. Recentered Influence Function (RIF)-regressions are used to decompose the role of differences in family characteristics and other labour market covariates and the differences in the way these latter are values in the labour market and protected by the net transfers. The approach is similar to an Oaxaca-Blinder decomposition, but the decomposition applies here on distributional measures instead of focusing on means (Firpo, Fortin and Lemieux, 2009, see Box B 1 for more technical details). These regressions are applied here to model the income distribution below the poverty line, i.e. up to the $25^{\text {th }}$ first quantile of equivalised income of households with children, and above the poverty line for the $50^{\text {th }}$ and the $75^{\text {th }}$ percentiles. 
117. For each country, changes in income are decomposed in two broad components to disentangle the contribution of changes in children's family characteristics and the "unexplained" part of the variation in child poverty that is not due to the identified changes in population characteristics. This decomposition, in practice, is formulated from the viewpoint of mid 2000s families and obtained by estimating the following equation:

$$
Z_{g i}=\alpha_{g 0}+\sum_{k=1}^{K} X_{i k} \beta_{g k}+\varepsilon_{g i}
$$

where $\mathrm{g}$ is an indicator of time, and $X_{i k}$ is a vector of control variables, including family demographics (age of parents, number of children, age of youngest child, education attainment of parents, household type, marital status and immigration status of parents, housing ownership), labour market statuses of parents, the intensity of work of parents (number of hours worked) the quality of jobs (occupation and industry for countries where this information is available). $Z_{g i}$ is a recentered influence function on the quantile of interest of the distribution of disposable equivalised income. Following the standard Oaxaca-Blinder decomposition, the estimated gap over time $\widehat{\Delta}_{0}^{\mu}=\bar{Z}_{t}-\overline{\bar{Z}}_{t-n}$ can be decomposed as:

$\widehat{\Delta}_{0}^{\mu}=\hat{\Delta}_{S}^{\mu}+\hat{\Delta}_{X}^{\mu}=\left[\sum_{k=1}^{K}\left(\bar{X}_{t k}-\bar{X}_{t-n k}\right) \hat{\beta}_{t k}\right]+\left[\left(\hat{\alpha}_{t 0}-\hat{\alpha}_{t-n 0}\right)+\sum_{k=1}^{K} \bar{X}_{t k}\left(\hat{\beta}_{t k}-\hat{\beta}_{t-n k}\right)\right]$

where the first term of equation 1 predict income quantiles that would apply if, for instance, children were "transported" into families with mid-2000s characteristics, but retained the 2014 returns to those characteristics. The group differences in the predictors are weighted by the coefficients of families' characteristics in 2014 to determine the endowments effect, the so called explained component. In other words, this latter measures the expected change in 2013 income quantiles, if those families had mid-2000s predictor levels.

118. By contrast, the second term estimates the portion of the evolution of income that is due to changes in the association between poverty and household characteristics applied to 2014 predictor levels; and it measures the income difference resulting from variations in the "returns" that family and work characteristics from one period to the other, differences which are mainly due to changes in the distribution of market income and in the structure of social transfers.

119. In all, this decomposition helps explain the factors that influence in the standard of living children in relative poverty (or in other words which influence the 'anchored' child poverty rate). An increase in the predicted income quantiles $\left(\widehat{\Delta}_{0}^{\mu}>0\right)$ (respectively a decrease, with $\left(\widehat{\Delta}_{0}^{\mu}<0\right)$ ) reflects a gain (resp. a decrease) in income at a given level of the income distribution, which can be interpreted either as a rise (resp. a decrease) in the standard of living or a decrease (resp. an increase) in anchored poverty.

120. Household (equivalised) income will increase or decrease, depending on the less/more favourable present family characteristics (as captured in the first term of equation 2 ) and on the evolution of the association between these characteristics and the position of children in household distribution. This second term of the equation will be positive if the "returns" to household characteristics improved as a consequence of better returns in the labour or capital market, or due to structural changes in transfers that overall make children better-off. It will be negative if the change in the effect of households characteristics is such that for children with same characteristics and same position in the income distribution, their income decreased. 


\section{Box B 1. Decomposing changes (or differences) with Recentered Influence Function regressions}

Decomposition analysis has become popular in labour economics especially with Oaxaca-Blinder decomposition of the gap that exists between the mean wage or income values of two group of population. The decomposition postulates linear relations between the outcome and its observable determinants, so that with conditional independent errors, the estimated gap can be decomposed in two parts: i) a so called explained component, which captures the role of differences in characteristics in explaining the gap in means; ii) and the unexplained part that is reflected in the differences in the regression coefficients obtained for the two groups of workers, and which relates to variations in how population' characteristics are rewarded or to the varying "income distribution" applying to different population groups.

The decomposition holds here because the coefficients $(\beta)$ of the regression $(Y=\beta X)$ can be interpreted as the effect of the characteristic $\mathrm{X}$ on the conditional mean [E (Y $\mid X)=X \beta]$; or the $\beta$ can be interpreted as the effect of the change in the mean value of $\mathrm{X}$ on the unconditional mean value of $\mathrm{Y}$. In other words, the law of Iterated expectations applies here, that is, $\mathrm{E}(\mathrm{Y})$ is simply a weighted average of averages, i.e. of the the $\mathrm{E}(\mathrm{Y} \mid \mathrm{X}=\mathrm{Cj})$, where the weight pj is the probability that $\mathrm{X}$ takes on the value of $\mathrm{Cj}$.

This latter property does not hold, however, when applying decomposition methods to distributional measures, such quantile regressions, which enables to examine the difference in each percentile of the distribution of income (Firpo and al., 2011). Regression coefficients then reflect the effect of characteristics on the conditional quantile but cannot be read as the unconditional effects, in which case the interpretation is limited (unless one estimates quantiles regressions for all quantiles). It turns then that one needs to know the entire conditional distribution of the outcome $\mathrm{Y}$ in each group $\mathrm{g}$ given $\mathrm{X}$ to compute the group-specific quantiles.

Estimating an entire conditional distribution function for each value of $(\mathrm{Yg} / \mathrm{X})$ is a difficult problem, however. A way to overcome this issue is to construct counterfactual distributions that integrate the conditional distribution of $\mathrm{Y}$ in a certain group given $\mathrm{X}$ over the distribution of $\mathrm{X}$ in the other group. Different approaches exist to estimate such counterfactual distributions but the simplest is to replace the distribution of population characteristics of a certain group by the distribution of $\mathrm{X}$ in the other group. This requires computing a reweighting factor which can be estimated using a simple logit or probit model for the probability of belonging to this latter group.

The decomposition for distributional measures then can be obtained by estimating counterfactual proportions with a linear model (or probit/logit model) for being below a given level of the dependent variable through counterfactual cumulative distributions which then can be inverted back to quantiles (Firpo, Fortin and Lemieux, 2009; 2011). The inverting function is then defined as Recentered influence Function (RIF) for which the law of Iterated Expectations holds so that a full Oaxaca-Blinder decomposition of the RIF for the quantile of interest can be performed. 


\section{Variables used for the analysis of material deprivation in Canada}

121. The Canadian Survey on Economic Well-Being (2013) provides information on the incidence of goods or activities that are lacking at the national and provincial geographies, at the household level in order to examine the basic economic needs and financial circumstances of households in Canada. The target population for this survey consists of all individuals in Canada, excluding residents of the Yukon, the Northwest Territories and Nunavut and residents of institutions and persons living on Indian reserves. The questions on material deprivation have been summarized as follows:

\begin{tabular}{|c|c|c|c|c|}
\hline No. & Variable name & CSEW variable(s) & Variable type & Description/definition \\
\hline 1 & Clothing & MD_14A & $\begin{array}{l}\text { Binary: } 1= \\
\text { Deprived; } 0= \\
\text { Not deprived }\end{array}$ & $\begin{array}{l}\text { Households are considered deprived (coded as "1") on 'Clothing' if they answer 'No } \\
\text { (2)' to the question MD_Q14A ("Do [you/you and each member of your household] } \\
\text { have at least two pairs of properly fitting footwear including a pair of suitable winter } \\
\text { footwear?") }\end{array}$ \\
\hline 2 & Nutrition & $\begin{array}{l}\text { MD_12A; } \\
\text { MD_13A }\end{array}$ & $\begin{array}{l}\text { Binary: } 1= \\
\text { Deprived; } 0= \\
\text { Not deprived }\end{array}$ & $\begin{array}{l}\text { Households are considered deprived (coded as "1") on 'Nutrition' if they answer 'No' } \\
\text { to either question MD_12A ("Do [you/you and each member of your household] eat } \\
\text { fresh fruits and vegetables at least once a day?") AND/OR MD_13A ("Do [you/you } \\
\text { and each member of your household] eat meat, chicken, fish or a vegetarian } \\
\text { equivalent } \\
\text { at least once a day?") }\end{array}$ \\
\hline 3 & Dental care & MD_09A & $\begin{array}{l}\text { Binary: } 1= \\
\text { Deprived; } 0= \\
\text { Not deprived }\end{array}$ & $\begin{array}{l}\text { Households are considered deprived (coded as "1") on 'Dental care' if they answer } \\
\text { 'No (2)' to the question MD_Q14A ("Are [you/you and each member of your } \\
\text { household] able to get regular dental care if needed?") }\end{array}$ \\
\hline 4 & $\begin{array}{l}\text { Leisure } \\
\text { opportunities }\end{array}$ & MD_16A & $\begin{array}{l}\text { Binary: } 1= \\
\text { Deprived; } 0= \\
\text { Not deprived }\end{array}$ & $\begin{array}{l}\text { Households are considered deprived (coded as "1") on 'Leisure opportunities' if they } \\
\text { answer 'No (2)' to the question MD_Q16A ("Do [you/you and each member of your } \\
\text { household] have a hobby or leisure activity?") }\end{array}$ \\
\hline 5 & $\begin{array}{l}\text { Internet access at } \\
\text { home }\end{array}$ & MD_05A & $\begin{array}{l}\text { Binary: } 1= \\
\text { Deprived; } 0= \\
\text { Not deprived }\end{array}$ & $\begin{array}{l}\text { Households are considered deprived (coded as "1") on 'Internet access at home' if } \\
\text { they answer 'No (2)' to the question MD_Q05A ("Do [you/you and your household] } \\
\text { have access to the Internet at home?") }\end{array}$ \\
\hline 6 & Housing conditions & $\begin{array}{l}\text { MD_06A; } \\
\text { MD_11A }\end{array}$ & $\begin{array}{l}\text { Binary: } 1 \text { = } \\
\text { Deprived; } 0= \\
\text { Not deprived }\end{array}$ & $\begin{array}{l}\text { Households are considered deprived (coded as "1") on 'Housing conditions' if they } \\
\text { answer 'No (2)' to either question MD_Q06A ("Are [you/you and your household] } \\
\text { able to keep your house or apartment at a comfortable temperature?") AND/OR } \\
\text { MD_Q11A("Is your house or apartment free of unwanted pests, such as } \\
\text { cockroaches, mice or bedbugs?"). }\end{array}$ \\
\hline
\end{tabular}

